Review

\title{
Recent Advances in Conjugated Polymer-Based Microwave Absorbing Materials
}

\author{
Ying Wang, Yunchen Du *, Ping Xu, Rong Qiang and Xijiang Han * \\ MIIT Key Laboratory of Critical Materials Technology for New Energy Conversion and Storage, School of \\ Chemistry and Chemical Engineering, Harbin Institute of Technology, Harbin 150001, China; \\ wangying901115@163.com (Y.W.); pxu@hit.edu.cn (P.X.); qiangrong2009@126.com (R.Q.) \\ * Correspondence: yunchendu@hit.edu.cn (Y.D.); hanxijiang@hit.edu.cn (X.H.); Tel.: +86-451-8641-8750
}

Academic Editor: Alexander Böker

Received: 20 September 2016; Accepted: 9 January 2017; Published: 14 January 2017

\begin{abstract}
Microwave absorbing materials (MAMs) are paving the way for exciting applications in electromagnetic (EM) pollution precaution and national defense security, as they offer an advanced alternative to conventional reflection principles to fundamentally eliminate the EM waves. Conjugated polymer (CP)-based composites appear as a promising kind of MAM with the desirable features of low density and high performance. In this review, we introduce the theory of microwave absorption and summarize recent advances in the fabrication of CP-based MAMs, including rational design of the microstructure of pure conjugated polymers and tunable chemical integration with magnetic ferrites, magnetic metals, transition metal oxides, and carbon materials. The key point of enhancing microwave absorption in CP-based MAMs is to regulate their EM properties, improve matching of characteristic impedance, and create diversified loss mechanisms. The examples presented in this review will provide new insights into the design and preparation of CP-based composites that can satisfy the high demands of the oncoming generation of MAMs.
\end{abstract}

Keywords: conjugated polymers; microwave absorbing materials; microstructure; composites; reflection loss

\section{Introduction}

The extensive utilization of communication devices-e.g., telecommunications, local area network systems, and radar systems-currently generates a large amount of electromagnetic (EM) waves into the living space of human beings. This serious EM emission leads to grim problem of EM interference (EMI), which not only causes damage to highly sensitive electronic equipment, but also has a remarkable negative effect on physical health [1-4]. To resolve the issues associated with EMI, numerous efforts have been made on EMI shielding referring to the essential blockage of EM radiation so that it cannot pass through the shielding layer [5]. However, the shielding materials are actually unable to dissipate EM emission due to their reflection principle for incident EM waves, and worse than that, they also produce secondary/repeated EMI pollution. In recent years, microwave-absorbing materials (MAMs) with low reflection and high absorption have received increasing attention due to their pragmatic and effective functions for reducing EMI pollution, because they can intrinsically convert the EM energy into thermal energy or dissipate EM waves through destructive interference [6,7].

To satisfy the requirements of practical applications, an eligible absorber should be labeled with some characteristic features, including being lightweight and thin, with powerful absorption and wide frequency bandwidth [8,9]. Generally, MAMs can be classified into two categories on the basis of their microwave loss mechanism: dielectric loss materials and magnetic loss materials [10]. Magnetic loss materials such as Fe [11], Co [12], Ni [13], and related ferrites [14,15] normally possess good 
microwave-absorbing performances in strong reflection loss and wide frequency response, while their high density and poor corrosion resistance restrict their sustainable development. In contrast, traditional dielectric loss materials such as $\mathrm{SiC}$ [16], $\mathrm{BaTiO}_{3}$ [17], carbon [18], and $\mathrm{ZnO}$ [19] also frequently suffer from mismatched impedance and narrower absorption bandwidth resulting from the relatively large gap between their relative complex permittivity and relative complex permeability. Therefore, developing novel MAMs with excellent performance is still a challenging task in the field of microwave absorption.

Since the discovery of conjugated polymers (CPs), many potential applications have been explored, ranging from organic electronic devices (such as polymer light-emitting diodes (PLEDs) [20,21], polymer solar cells (PSCs) [22,23], organic field effect effect transistors (OFETs) [24,25], and chemo-/bio-sensors $[26,27]$. Different from traditional polymers, the $\pi$-conjugated main chains in CPs give them a delocalized electronic structure which endows them with unusual electronic properties, such as electrical conductivity, low energy optical transitions, low ionization potential, and high electron affinity [28]. The high electrical conductivity gifted by the extended $\pi$-conjugated system even gains them the name of "synthetic metal". As a result, they have been widely studied as EM shielding materials in earlier studies [29-31]. However, it was also found that the shielding effectiveness of CPs came partially from their available microwave absorption performance rather than just from reflection [31]. This valid absorption performance motivated a great deal of research work on developing novel MAMs based on various CPs. In addition, the unique advantages of CPs (e.g., low density, low cost, resistance to corrosion, and ease of preparation [32]) also render them as one kind of the most promising candidates for MAMs in practical applications. To date, CP-based MAMs have made significant achievements in the field of microwave absorption through rational design on microstructure and hybridization with different types of materials [33,34]. With more and more publications in this field, a comprehensive summary and review of the published research results and relevant theory will be very helpful to further promote the development of the microwave absorption of CP-based MAMs. Therefore, in this review, we not only summarize theoretical calculations, loss mechanisms, and evaluation methods, but also highlight the recent advances of CP-based MAMs, including pure $\mathrm{CPs}$, magnetic ferrites/CP composites, magnetic metal/CP composites, transition metal oxides/CP composites, carbon/CP composites, multi-compound CP-based composites, and multi-layer CP-based composites. Furthermore, the shortcomings, challenges, and prospects of CP-based MAMs are also discussed.

\section{Theory of Microwave Absorption}

EMI shielding and microwave absorption are two common strategies to resist the interference of incident EM waves, while they are generally evaluated by different measurement models because of their distinguishable concerns. For a conventional EMI shielding model (Figure 1a), the most important thing is to attenuate the intensity of the transmission EM waves, and a common parameter-shielding effectiveness (SE) - is employed to describe the relationship between the transmission wave and the incident wave (wave (1) and wave (4) in Figure 1a), which can be defined as

$$
\mathrm{SE}=R+A+B
$$

where $R$ is the reflection loss, $A$ is the absorption loss, and $B$ stands for the multiple reflection loss [35]. In this case, high reflectivity is very favorable to the SE, and most incident waves are reflected off the surface of shielding materials. The physical significance of reflection loss in EMI shielding is the difference between the initial incident waves and those waves penetrating into the shielding materials (wave (1) and wave (2) in Figure 1a). For the model of microwave absorption (Figure 1b), however, a metal substrate is placed to reflect the transmission waves. As a result, the transmission waves are always negligible in microwave absorption. Reflection loss herein means the difference between the initial incident waves and the final reflected waves (wave (1) and wave (4) in Figure 1b). 
The final reflected waves include all back-propagation EM waves reflected at various surfaces and interfaces, and ideal MAMs should weaken the reflected waves as much as possible. Relative complex permittivity $\left(\varepsilon_{\mathrm{r}}=\varepsilon^{\prime}-j \varepsilon^{\prime \prime}\right)$ and relative complex permeability $\left(\mu_{\mathrm{r}}=\mu^{\prime}-j \mu^{\prime \prime}\right)$ are very important parameters that can determine the microwave absorption properties of an absorber. The real parts of relative complex permittivity $\left(\varepsilon^{\prime}\right)$ and relative complex permeability $\left(\mu^{\prime}\right)$ are on behalf of the storage capability of electric and magnetic energy, and the imaginary parts $\left(\varepsilon^{\prime \prime}\right.$ and $\left.\mu^{\prime \prime}\right)$ describe the loss capability of electric and magnetic energy [36]. On the basis of relative complex permittivity and relative complex permeability, the reflection loss $\left(R_{\mathrm{L}}(\mathrm{dB})\right)$ properties of an absorber can be deduced from the transmission line theory [37]:

$$
R_{L}(\mathrm{~dB})=20 \log \left|\frac{Z_{\text {in }}-1}{Z_{\text {in }}+1}\right|
$$

$Z_{\text {in }}$ refers to the normalized input impedance of a metal-backed microwave absorbing layer, and is given by

$$
Z_{\text {in }}=\sqrt{\frac{\mu_{\mathrm{r}}}{\varepsilon_{\mathrm{r}}}} \tanh \left[j\left(\frac{2 \pi}{c}\right) f d \sqrt{\mu_{\mathrm{r}} \varepsilon_{\mathrm{r}}}\right]
$$

where $c$ is the velocity of EM waves in free space, $f$ is the microwave frequency, and $d$ is the thickness of an absorber. It is widely accepted that dielectric loss ability mainly comes from conductivity loss and polarization loss [38,39], and the polarization loss can be further divided into ionic polarization, electronic polarization, dipole orientation polarization, and interfacial polarization (space charge polarization) [40]. According to the free electron theory [41], $\varepsilon^{\prime \prime} \approx 1 / 2 \pi \rho f \varepsilon_{0}$, where $\rho, f$, and $\varepsilon_{0}$ are the resistivity, the frequency, and the dielectric constant of free space, respectively, it can be expected that high electric conductivity (i.e., low resistivity) will enhance the imaginary parts of relative complex permittivity. Ionic polarization and electronic polarization can be easily excluded in microwave absorption because they usually occur at a much higher frequency region $\left(10^{3}-10^{6} \mathrm{GHz}\right)$ [40]. Dipoles-namely, bound charges in dielectric medium-are generally restricted on the defects and residual groups, and cannot move freely like electrons in an external electric field. Under a high-frequency alternating electric field, the dipoles cannot reorient themselves quickly enough to respond to the applied electric field, resulting in dipole orientation polarization [42]. At the same time, $\varepsilon^{\prime}$ and $\varepsilon^{\prime \prime}$ will start to decrease and produce typical frequency dispersion behaviors [42]. The contribution from interfacial polarization always appears in a heterogeneous system, and the accumulation and uneven distribution of space charges at the interfaces will produce a macroscopic electric moment that can consume the incident EM energy effectively $[43,44]$. To better understand the polarization relaxations, Cole and Cole reinterpreted the classical Debye equations into [45]

$$
\left(\varepsilon^{\prime}-\varepsilon_{\infty}\right)^{2}+\varepsilon^{\prime \prime 2}=\left(\varepsilon_{s}-\varepsilon_{\infty}\right)^{2}
$$

where $\varepsilon_{\mathrm{S}}$ and $\varepsilon_{\infty}$ are the static dielectric constant and the dielectric constant at infinite frequency, respectively. If there is a polarization relaxation process, the plot of $\varepsilon^{\prime \prime}$ versus $\varepsilon^{\prime}$ will be a single semicircle, which is also defined as the Cole-Cole semicircle. To better illustrate the application of the Cole-Cole semicircle, Figure 2 displays the plots of $\varepsilon^{\prime \prime}$ versus $\varepsilon^{\prime}$ of metallic Co and core-shell Co@C microspheres in wax matrix [46]. As observed, metallic Co gives only one semicircle due to the interfacial polarization relaxation between Co and wax, while Co@C microspheres display at least three semicircles in the studied frequency range. The additional semicircles in Co@C microspheres mean more relaxations from multiple interfacial polarizations and dipole orientation polarization. 


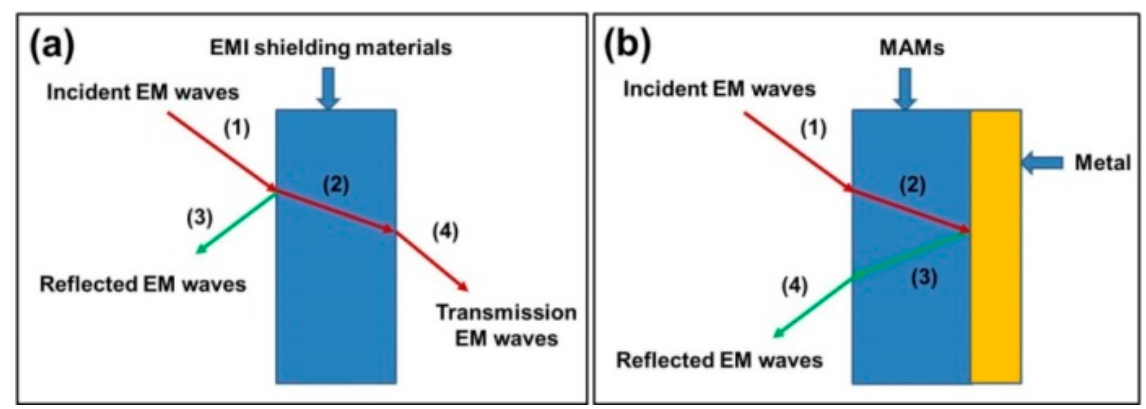

Figure 1. The evaluation models of (a) conventional electromagnetic interference (EMI) shielding and (b) microwave absorption. MAM: microwave-absorbing material.

(a)

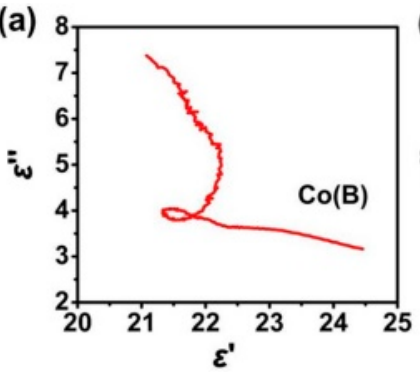

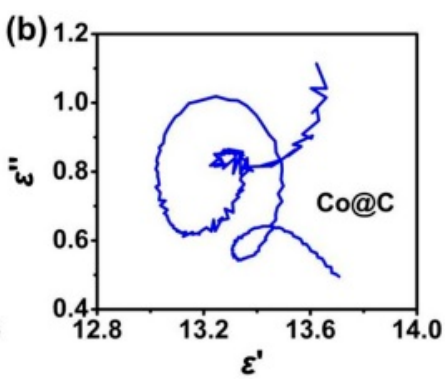

Figure 2. Plots of $\varepsilon^{\prime \prime}$ versus $\varepsilon^{\prime}$ for (a) metallic Co and (b) core-shell Co@C microspheres. Reprinted with permission from Reference [46].

Magnetic loss usually becomes active in the presence of magnetic components in MAMs, and it mainly originates from hysteresis, domain wall resonance, natural ferromagnetic resonance, and eddy current effect [47]. However, natural ferromagnetic resonance and eddy current effect are taken as two dominant factors that contribute to magnetic loss, because the hysteresis loss is negligible in the weak EM field and domain wall resonance only occurs at much lower frequency (1-100 MHz) [47]. According to the ferromagnetic resonance theory [48], the natural ferromagnetic resonance frequency correlates to an anisotropy field which can be expressed by the equation

$$
f_{\mathrm{r}}=(\gamma / 2 \pi) H_{\mathrm{eff}}
$$

where $f_{\mathrm{r}}$ is the resonance frequency, $\gamma$ is the gyromagnetic ratio, and $H_{\text {eff }}$ is the effective anisotropy field. As the smaller magnetic particles can lead to an enhanced effective anisotropy, the ferromagnetic resonance in high-frequency range can be expected by decreasing the size of the magnetic particle [49]. The eddy current loss is universal in ferromagnetic conductors and it can be expressed by [50]:

$$
\mu^{\prime \prime}=2 \pi \mu_{0}\left(\mu^{\prime}\right)^{2} \sigma \cdot d^{2} f / 3
$$

where $\sigma\left(\mathrm{S} \cdot \mathrm{m}^{-1}\right)$ is the electrical conductivity and $\mu_{0}\left(\mathrm{H} \cdot \mathrm{m}^{-1}\right)$ is the permeability in vacuum. If the microwave attenuation only results from the eddy current effect, the values of $\mu^{\prime \prime}\left(\mu^{\prime}\right)^{-2} f^{-1}$ will be constant under varied frequency $[47,49]$. It is worth noting that the particle size of the ferromagnetic conductor always plays an important role in determining the eddy current effect. Once the particle size exceeds the critical value, a strong eddy current will generate a skin effect, resulting in the partial invalidation of the internal magnetic field and consequent degradation of relative complex permeability. Therefore, decreasing the particle size of the ferromagnetic conductor and constructing multi-component composites are two familiar strategies to suppress the skin effect [51,52]. Although some common magnetic parameters—such as saturation magnetization $\left(M_{\mathrm{S}}\right)$ and coercivity 
$\left(H_{\mathrm{C}}\right)$ —cannot be intuitively linked with magnetic loss, another important concept, initial permeability $\left(\mu_{\mathrm{i}}\right)$, is usually employed to predict magnetic loss ability [13,53], and can be expressed by

$$
\mu_{\mathrm{i}}=\frac{M_{\mathrm{s}}^{2}}{a k H_{\mathrm{c}} M_{\mathrm{s}}+b \lambda \zeta}
$$

where $a$ and $b$ are two constants determined by the material composition, $\lambda$ is the magnetostriction constant, and $\xi$ is an elastic strain parameter of the crystal. For ferromagnetic MAMs, high $\mu_{\mathrm{i}}$ will favor strong magnetic loss ability, and it can be concluded from Equation (7) that larger $M_{\mathrm{S}}$ and smaller $H_{\mathrm{C}}$ may contribute to the improvement of $\mu_{\mathrm{i}}$ value.

For direct evaluation of the dielectric loss and magnetic loss abilities, two common concepts-dielectric dissipation factor $\left(\tan \delta_{\mathrm{e}}=\varepsilon^{\prime \prime} / \varepsilon^{\prime}\right)$ and magnetic dissipation factor $\left(\tan \delta_{\mathrm{m}}=\right.$ $\left.\mu^{\prime \prime} / \mu^{\prime}\right)$ - are widely utilized. Although a large dielectric dissipation factor and magnetic dissipation factor are desirable in MAMs, the specific microwave absorption does not simply depend on dielectric loss ability or magnetic loss ability. There is another important parameter-the concept of matched characteristic impedance, relating to the reflection loss properties of various MAMs-that can determine the transmission behaviour of incident EM waves [54]. In theory, the characteristic impedance of MAMs should be equal/close to that of the free space (377 $\Omega$ ) to achieve zero-reflection at the front surface of the materials [54]. If the characteristic impedance is well matched, most EM waves can enter into MAMs to be converted into thermal energy or dissipated through interference; otherwise, most EM waves will be reflected at the front surface of MAMs or pass through the MAMs without any dissipation $[55,56]$. Recently, Ma et al. proposed a delta-function method to validate the impedance matching degree of various absorbers by the following equation [57]:

$$
|\Delta|=\left|\sinh ^{2}(K f d)-M\right|
$$

where $|\Delta|$ represents the impedance mismatch degree, and $K$ and $M$ are determined by the relative complex permittivity and permeability

$$
\begin{gathered}
K=\frac{4 \pi \sqrt{\mu^{\prime} \varepsilon^{\prime}} \cdot \sin \frac{\delta_{\mathrm{e}}+\delta_{\mathrm{m}}}{2}}{c \cdot \cos \delta_{\mathrm{e}} \cos \delta_{\mathrm{m}}} \\
M=\frac{4 \mu^{\prime} \cos \delta_{\mathrm{e}} \varepsilon^{\prime} \cos \delta_{\mathrm{m}}}{\left(\mu^{\prime} \cos \delta_{\mathrm{e}}-\varepsilon^{\prime} \cos \delta_{\mathrm{m}}\right)^{2}+\left[\tan \left(\frac{\delta_{\mathrm{m}}}{2}-\frac{\delta_{\mathrm{e}}}{2}\right)\right]^{2}\left(\mu^{\prime} \cos \delta_{\mathrm{e}}+\varepsilon^{\prime} \cos \delta_{\mathrm{m}}\right)^{2}}
\end{gathered}
$$

Therefore, higher absorption at a thickness is the result of better impedance match, where $|\Delta|$ is close to zero. If characteristic impedance of MAMs is not satisfying the criteria, $|\Delta|$ tends to stay away from zero, giving poor microwave absorption.

\section{Pure CPs as MAMs}

Although the microwave absorption ability of CPs has been recognized in earlier study, the performance of pure CPs is not that exciting, because their relatively high relative complex permittivity and quite low relative complex permeability are not favorable for the matching of characteristic impedance, resulting in serious deviation from the zero-reflection condition at the surface of MAMs [54]. Chandrasekhar et al. investigated the microwave shielding and absorption of bulk polyaniline (PANI) doped with two proprietary sulfonate dopants, and they found that bulk PANI has good shielding effectiveness ( $<-15 \mathrm{~dB}$ over 4 to $18 \mathrm{GHz}$ ) and poor absorption performance (about $-5 \mathrm{~dB}$ in $\mathrm{X}$ and $\mathrm{K}$ bands) [31]. Very interestingly, recent progress indicates that rational design on the microstructure of CPs will be an effective strategy to regulate the EM properties, improve the matching of characteristic impedance, and enhance the microwave absorption. For example, Zhang et al. prepared PANI nanofibers and nanoparticles by interfacial polymerization method, and the resultant PANI nanofibers 
exhibited uncommon negative relative complex permittivity and dielectric dissipation factor [58]. Sun et al. reported that PANI microrods could show stronger reflection loss than conventional PANI [59]. Xie et al. designed an ultralight three-dimensional (3D) polypyrrole (PPy) aerogel and (3D) polypyrrole/poly(3,4-ethylenedioxythioxythiophene) (PPy/PEDOT) hybrid composite by a facile self-assembled polymerization method, and the effective EM absorption bandwidth $(<-10 \mathrm{~dB}, 90 \%$ absorption) could reach up to $6.2 \mathrm{GHz}[60,61]$. Our group previously performed the synthesis of PANI nanoparticles using a reverse dropping method with PVP (Polyvinylpyrrolidone) as a steric stabilizer [62]. The morphology of PANI was highly dependent on the dropping rate (Figure 3a), and well-dispersed PANI nanoparticles could only be obtained under optimum conditions (Figure 3b,c). The different dropping rate also led to significant changes in the length and oxidation-state of conjugated chains, and thus the resultant products presented quite distinguishable EM properties and microwave absorption characteristics. Especially, PANI-NP1 and PANI-NP2-consisting of well-dispersed nanoparticles-displayed substantially enhanced reflection loss as compared with conventional PANI (C-PANI) (Figure 3d).

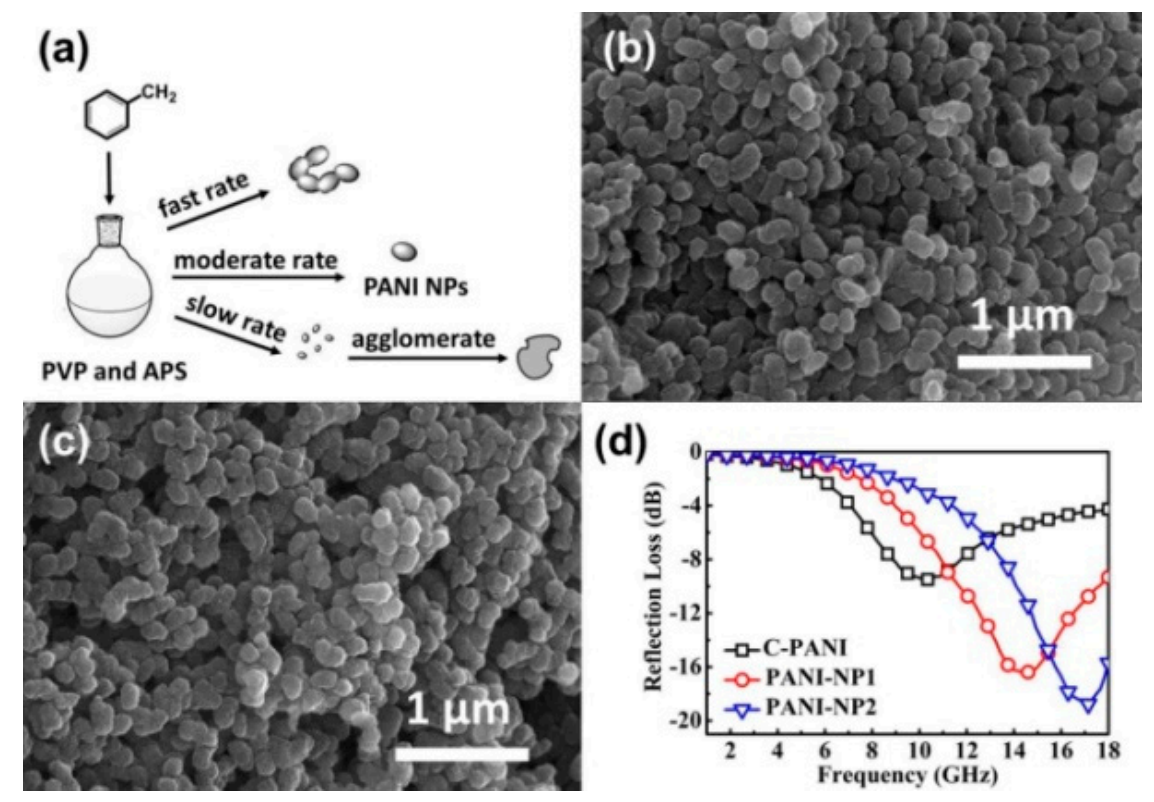

Figure 3. (a) Schematic illustration of the possible mechanism for polyaniline (PANI) nanoparticles (NPs); SEM images of (b) PANI-NP1 and (c) PANI-NP2; (d) Reflection-loss curves of conventional PANI (C-PANI), PANI-NP1, and PANI-NP2 with an absorber thickness of $2 \mathrm{~mm}$ in the frequency range of 1-18 GHz. Reprinted with permission from Reference [62]. APS: ammonium persulfate; PVP: Polyvinylpyrrolidone.

According to the transmission line theory, multiple reflections or scattering inside absorbers can promote the attenuation of incident EM waves [35]. Therefore, it is of great significance to create some unique microstructure (e.g., hollow, core-shell, yolk-shell) in CPs, which can facilitate multiple reflections/scatterings to further enhance microwave absorption. As shown in Figure 4a-d, multi-shelled PEDOT hollow microspheres were generated by using $\mathrm{Fe}_{3} \mathrm{O}_{4}$ hollow microspheres as sacrificial templates via a programmed reaction-temperature process [34]. It could be found that with an increase in the number of shells, the microwave absorption properties of PEDOT microspheres were obviously enhanced (Figure 4e). The maximum $R_{\mathrm{L}}$ values of the triple-shelled and double-shelled PEDOT were 39.7 and $32.4 \mathrm{~dB}$, respectively, at a thickness of $2 \mathrm{~mm}$, which are higher than those of PEDOT solid particles $(19.2 \mathrm{~dB})$ and single-shelled PEDOT $(26.5 \mathrm{~dB})$. The excellent microwave absorption performance of the multiple-shelled PEDOT microspheres was attributed to the following aspects: (1) the existing interfacial polarization between multiple core/shell/shell gradient interfaces 
were extremely favorable for EM attenuation; (2) high void space in these multiple shell microspheres provided more active sites for the reflection and scattering of incident EM waves than the solid PEDOT microspheres. By considering the importance of interfacial polarization, our group also constructed highly uniform core-shell PPy@PANI composites with controllable PANI shell thickness [34]. The as-prepared composites showed much better microwave absorption than individual PPy microspheres and PANI. Investigations on the mechanism indicated that interfacial polarization contributed to the dielectric loss significantly, which was beneficial for the creation of well-matched characteristic impedance in these core-shell composites and producing strong reflection loss.

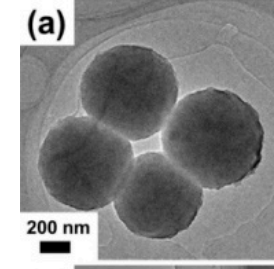

(c)

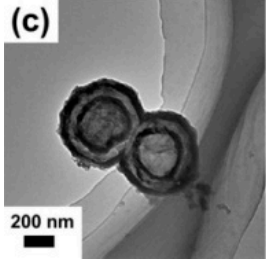

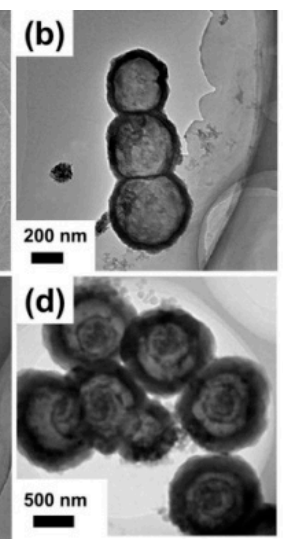

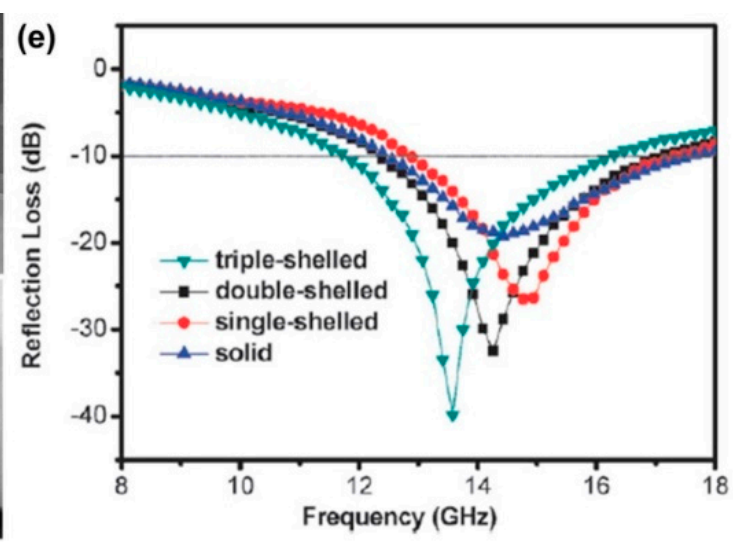

Figure 4. (a) TEM images of poly(3,4-ethylenedioxythioxythiophene (PEDOT) solid spheres; (b) single-shelled PEDOT hollow spheres; (c) double-shelled PEDOT microspheres; and (d) triple-shelled PEDOT microspheres; (e) Reflection loss for different morphologies of PEDOT microspheres in the frequency range of $8.0-18.0 \mathrm{GHz}$ with a thickness of $2 \mathrm{~mm}$. Reprinted with permission from Reference [34].

\section{CP-Based Composites as MAMs}

Compared with the design of $\mathrm{CP}$ microstructure, there have been more tremendous interests in constructing $\mathrm{CP}$-based heterogeneous nanocomposites for microwave absorption applications, because the embedment of heterogeneous components into the $\mathrm{CP}$ matrix is a relatively simple approach to manipulating the EM properties and creating additional loss mechanisms. To date, various magnetic ferrites, magnetic metals, transition metal oxides, and diversified carbon materials have been extensively coupled with CPs to produce novel MAMs with better performance.

\subsection{Magnetic Ferrites/CP Composites}

As a kind of typical magnetic material, spinel ferrites (e.g., $\mathrm{Fe}_{3} \mathrm{O}_{4}, \gamma-\mathrm{Fe}_{2} \mathrm{O}_{3}, \mathrm{CoFe}_{2} \mathrm{O}_{4}, \mathrm{NiFe}_{2} \mathrm{O}_{4}$, $\mathrm{Mn}_{1-x} \mathrm{Zn}_{x} \mathrm{Fe}_{2} \mathrm{O}_{4}$ ) have been taken as the most common additives in CP-based MAMs due to their simple chemical composition and mild preparation [63-77]. For example, Yang et al. decorated hollow PANI microspheres with well-dispersed $\mathrm{Fe}_{3} \mathrm{O}_{4}$ nanoparticles, and they found that the resultant composites could produce much better reflection loss characteristics than sole PANI microspheres [66]. Gandhi et al. synthesized conducting ferromagnetic polyaniline- $\mathrm{CoFe}_{2} \mathrm{O}_{4}$ nanocomposites via the one-step chemical oxidative polymerization of aniline in the presence of $\mathrm{CoFe}_{2} \mathrm{O}_{4}$ nanoparticles (30-40 nm), and the incorporation of $\mathrm{CoFe}_{2} \mathrm{O}_{4}$ nanoparticles was confirmed to be responsible for the enhanced absorption effectiveness in the frequency range of $12.4-18.0 \mathrm{GHz}$ (Ku band) [70]. Li et al. coated flake-like $\mathrm{NiFe}_{2} \mathrm{O}_{4}$ with PANI and PPy, respectively, and EM analysis revealed that the $\mathrm{NiFe}_{2} \mathrm{O}_{4} / \mathrm{PPy}$ composite would be an eligible candidate for microwave absorption [77]. Although an expected improvement in properties can be achieved by these composites, it is important to mention that spinel ferrite particles are usually randomly distributed in the matrix of $\mathrm{CPs}$, and the poor chemical homogeneity will not be favorable for their practical applications [32,55]. As a result, some uniform core-shell composites were elaborately 
developed to remedy the drawbacks in conventional composites [78,79]. As observed in Figure 5, the uniformly continuous PANI coating on the surface of $\mathrm{Fe}_{3} \mathrm{O}_{4}$ nanoparticles provided excellent chemical homogeneity, and the synergistic effect between PANI coating and $\mathrm{Fe}_{3} \mathrm{O}_{4}$ nanoparticles could guarantee the enhanced microwave absorption performance as compared with independent PANI and $\mathrm{Fe}_{3} \mathrm{O}_{4}[78]$.
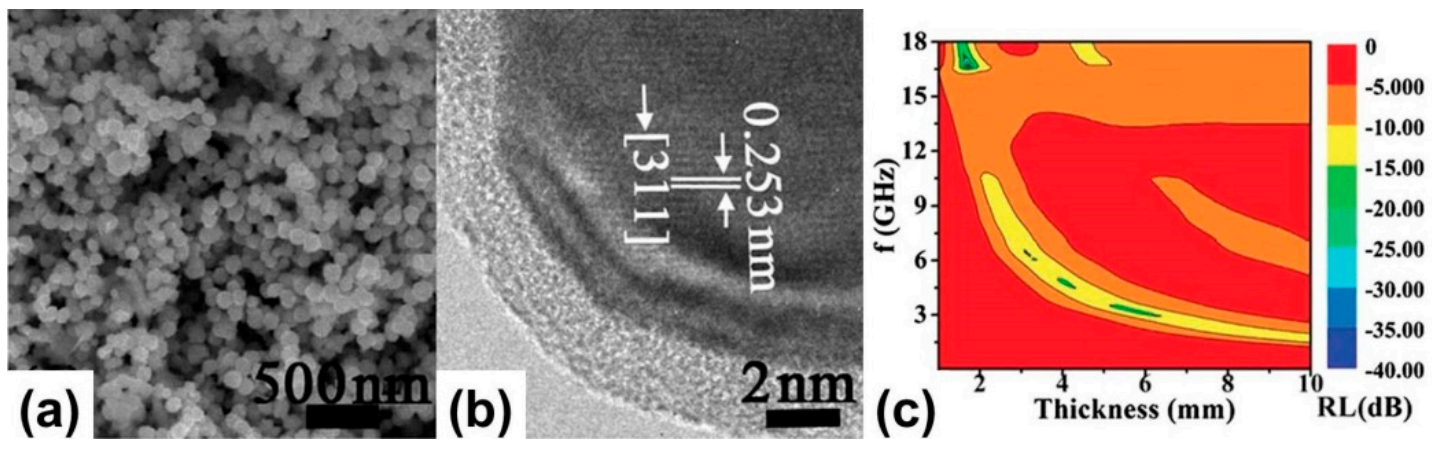

Figure 5. (a) SEM image; (b) HRTEM (High Resolution Transmission Electron Microscopy) image; and (c) two-dimensional (2D) representation of the $R_{\mathrm{L}}$ of $\mathrm{Fe}_{3} \mathrm{O}_{4}-\mathrm{PANI}$ nanoparticles. Reprinted with permission from Reference [78].

Moreover, it is worth noting that most composites mentioned above are fabricated from spinel ferrite nanoparticles (ca. 10-100 nm), which usually show very limited permeability in the gigahertz range due to the Snoek's limit [80], and thus the enhancement of the microwave absorption of these composites is more dependent on the optimized dielectric loss rather than a combination of dielectric and magnetic loss [79]. Inspired by the successful breakthrough of Snoek's limit in some unique aggregates of spinel ferrite nanoparticles [11,14,81-85]—including urchin-like structure, loose/hollow microsphere, dendrite-like structure, and mesoporous structure-more and more efforts have been devoted to the construction of CP-based composites based on the assembly of spinel ferrite nanoparticles [86-89]. A two-step oxidative polymerization of aniline monomers was conducted in the presence of $\mathrm{Fe}_{3} \mathrm{O}_{4}$ microspheres with $\mathrm{Fe}^{3+}$ and ammonium persulfate (APS) as the oxidants in each step, so that a novel "egg-like" composite of $\mathrm{Fe}_{3} \mathrm{O}_{4}$ microspheres/PANI could be generated (Figure 6) [86]. It was found that embedded $\mathrm{Fe}_{3} \mathrm{O}_{4}$ microspheres would not only modulate the relative complex permittivity but also produce significant magnetic resonance and loss in the composite. More importantly, the composites prepared from the two-step oxidative polymerization using hierarchical magnetic materials had better microwave absorption and environmental stability compared with composites produced by embedding $\mathrm{Fe}_{3} \mathrm{O}_{4}$ nanoparticles, one-step oxidative polymerization, or physical mixture. If the amount of monomers can be precisely controlled or an external field is applied for magnetic collection, various well-defined core-shell composites of $\mathrm{Fe}_{3} \mathrm{O}_{4}$ microspheres and CPs would be obtained [87-89]. As shown in Figure 7, the PPy shell thickness can be adjusted from 20 to $80 \mathrm{~nm}$ with the variation of the ratio of pyrrole to $\mathrm{Fe}_{3} \mathrm{O}_{4}$ [89]. Investigations of the microwave absorbing properties indicate that the PPy shell plays an important role, and the maximum reflection loss of composite microspheres can reach as much as $-31.5 \mathrm{~dB}(>99.9 \%$ absorption) at $15.5 \mathrm{GHz}$ with a matching layer thickness of $2.5 \mathrm{~mm}$. Compared to the physically blended $\mathrm{Fe}_{3} \mathrm{O}_{4}-\mathrm{PPy}$ composites, $\mathrm{Fe}_{3} \mathrm{O}_{4} @$ PPy composite microspheres not only possess better reflection loss performance, but also have a wider absorbing bandwidth of $5.2 \mathrm{GHz}(12.8-18.0 \mathrm{GHz})$ in the $\mathrm{Ku}$ band, which is attributed to the intensive synergistic effect of dielectric loss from PPy shells and magnetic loss from $\mathrm{Fe}_{3} \mathrm{O}_{4}$ cores. 
(a)
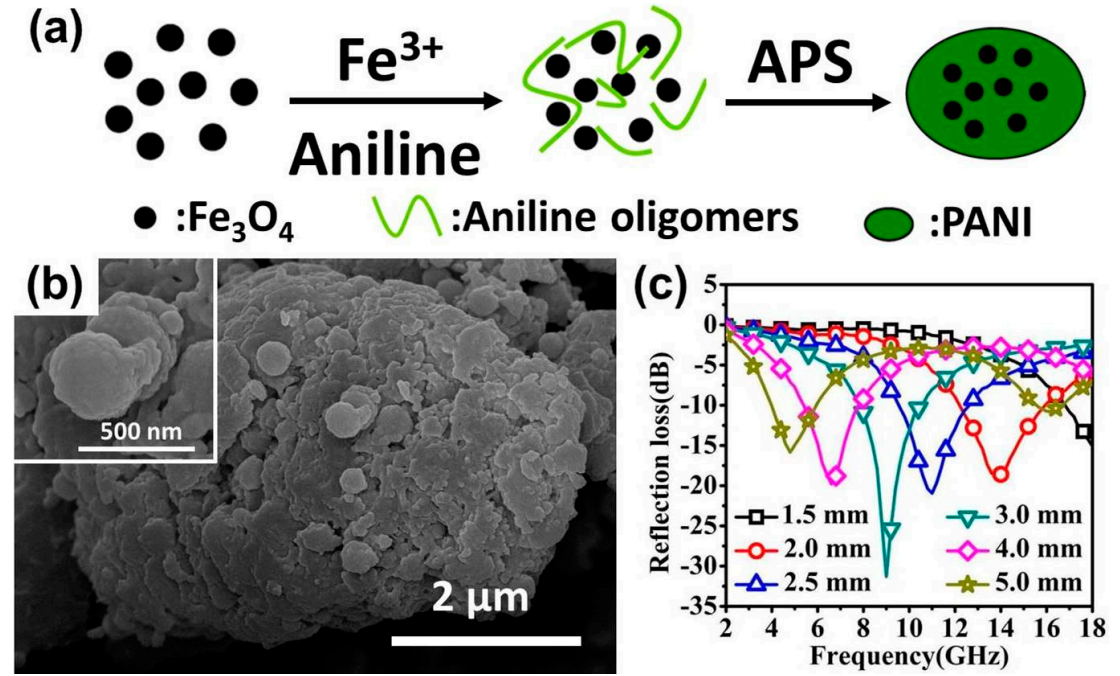

Figure 6. (a) Possible formation mechanism; (b) SEM image; and (c) reflection loss curves dependent on the thickness of "egg-like" $\mathrm{Fe}_{3} \mathrm{O}_{4}$ microspheres/PANI composites. Reprinted with permission from Reference [86].
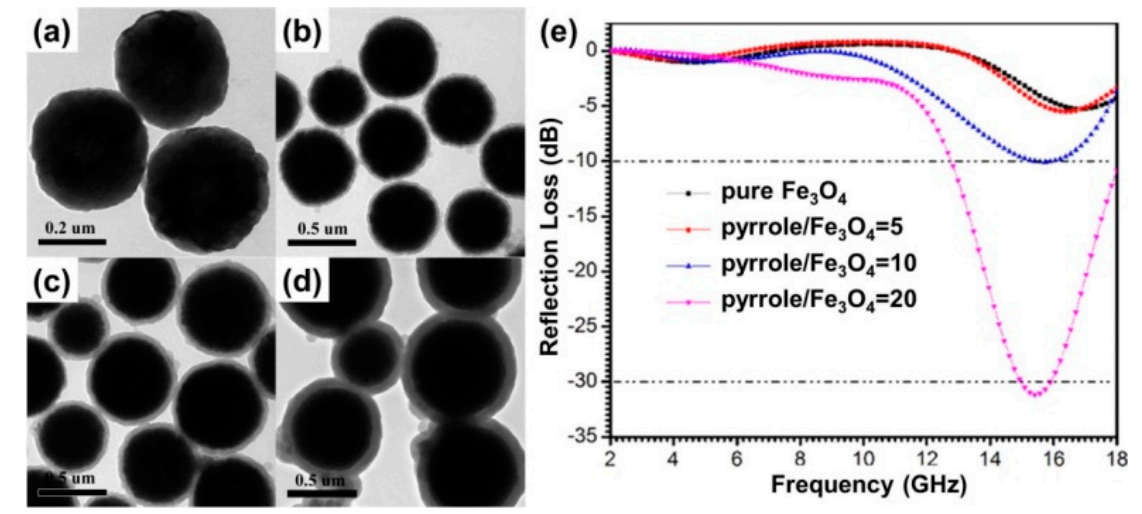

Figure 7. TEM images of (a) pure $\mathrm{Fe}_{3} \mathrm{O}_{4}$ microspheres and $\mathrm{Fe}_{3} \mathrm{O}_{4} @$ PPy core-shell composite microspheres prepared with different pyrrole/ $\mathrm{Fe}_{3} \mathrm{O}_{4}$ ratios: (b) 5; (c) 10; and (d) 20; and (e) their microwave reflection losses (absorber thickness $=2.5 \mathrm{~mm}$ ) in the frequency range of $2-18 \mathrm{GHz}$. Reprinted with permission from Reference [89].

In addition to spinel ferrites, the hexagonal ferrites-including M-type, W-type, X-type, Y-type, Z-type, and U-type-are also of great interest as high-frequency MAMs because of their planar magnetic anisotropy and natural resonance in the gigahertz range [90-92]. M-type barium ferrites $\left(\mathrm{BaFe}_{12} \mathrm{O}_{19}\right)$ and strontium ferrites $\left(\mathrm{SrFe}_{12} \mathrm{O}_{19}\right)$ are two typical examples of the hexagonal group that possess very strong uniaxial anisotropy, high saturation magnetization, and significant permeability [93,94], and thus the integration of $\mathrm{BaFe}_{12} \mathrm{O}_{19} / \mathrm{SrFe}_{12} \mathrm{O}_{19}$ and CPs took a considerable share in the field of high-performance MAMs in the past decade [42,95-102]. However, high-temperature sintering $\left(>800^{\circ} \mathrm{C}\right)$ is always necessary for the formation of hexagonal ferrites [103], which results in serious agglomeration of ferrite particles and consequent difficulty in controlling the microstructure of the corresponding composites. This situation limits the development of this kind of MAMs to some extent. Wang et al. reported the synthesis of core-shell $\mathrm{BaFe}_{12} \mathrm{O}_{19} / \mathrm{PANI}$ nanocomposites with controlled shell thickness by employing $\mathrm{BaFe}_{12} \mathrm{O}_{19}$ nanoparticles derived from sol-gel auto-combustion method as the nucleation sites of PANI [104]. The relatively small particle size more or less improved the homogeneity of $\mathrm{BaFe}_{12} \mathrm{O}_{19} / \mathrm{PANI}$ nanocomposites, and strong reflection loss over a wide frequency range could be achieved with optimum shell thickness. These results 
provided a hint that the microwave absorption performance of hexagonal ferrite/CP composites could be further reinforced by reasonable excogitation on the microstructure of the hexagonal ferrite particles. On the other hand, oriented ion substitution in hexagonal ferrites was also confirmed to be a positive method to enhance the microwave absorption performance of hexagonal ferrite/CP composites [105], which might be attributed to the fact that substituted hexagonal ferrites with different magnetic loss and dielectric loss abilities changed the synergetic/complementary behavior between organic and inorganic components [105-107]. In view of this, the latest results on the composites of hexagonal ferrites and CPs are mostly constructed with the heteroatoms-substituted hexagonal ferrites [108-112].

\subsection{Magnetic Metal/CP Composites}

Magnetic metal nanoparticles (e.g., $\mathrm{Fe}, \mathrm{Co}, \mathrm{Ni}$, and their related alloys) generally possess large saturation magnetization, high Snoek's limit, compatible dielectric loss, and distinguishable permeability in the gigahertz frequency range, which make them better magnetic candidates that can satisfy the design requirements of high-performance MAMs as compared with conventional ferrites [113,114]. However, acidic and oxidative conditions for the polymerization of CPs are unfavorable for magnetic metal nanoparticles, and thus there are only a few accessible papers on the microwave absorption of magnetic metal/CP composites. Dong et al. and $\mathrm{Xu}$ et al. prepared $\mathrm{Ni} / \mathrm{PANI}$ and $\mathrm{Ni} / \mathrm{PPy}$ composites, respectively, through an in situ chemical oxidative polymerization of monomer in the presence of commercial Ni powder $[115,116]$. The resultant Ni/PANI and Ni/PPy composites display multiple dielectric relaxations and a natural magnetic resonance. The multiple relaxations for enhanced dielectric loss induced by CPs coatings and proper EM impedance matching due to the synergetic consequence of the $\mathrm{Ni}$ cores and polymer shells contribute to the improvement of the EM absorption. Co/PPy composite could be produced with the same method, and its effective microwave absorption was observed in the frequency range of $10.0-18.0 \mathrm{GHz}$ with an absorber thickness of $3.0 \mathrm{~mm}$ [117]. More recently, Han et al. embedded superparamagnetic Ni nanoparticles in PANI nanocomposites through a simple oxidation-reduction method followed by an in situ polymerization process [118]. The Ni nanoparticles with single crystalline and single magnetic domain structure possess an average diameter of $\sim 2.1 \mathrm{~nm}$ (Figure 8a,b). Such a paramagnetic system with large magnetic moment, fast reaction response to the applied magnetic field, and negligible remanence is beneficial for the formation of antiresonance behavior in permeability. The combined effect of dielectric and magnetic loss is responsible for its excellent microwave absorption, where the optimal reflection loss value of Ni@PANI composites reaches $-22.98 \mathrm{~dB}$ at $17.8 \mathrm{GHz}$, corresponding to a very thin absorber thickness of $1.0 \mathrm{~mm}$ (Figure 8c).
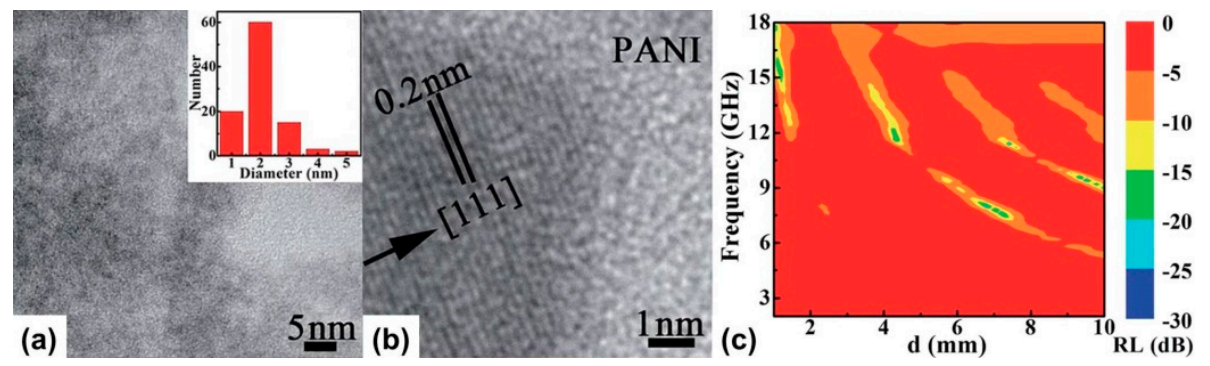

Figure 8. TEM image of (a) Ni@PANI nanocomposite and (b) HRTEM image of one Ni nanoparticle. The inset in (a) shows the size distribution of the Ni nanoparticles; (c) Color map of calculated reflection loss values with the thickness of $1.0-10.0 \mathrm{~mm}$ as a function of frequency. Reprinted with permission from Reference [118].

\subsection{Transition Metal Oxide/CP Composites}

The embedment of magnetic ferrites or metals in CPs indeed brings significant enhancement in microwave absorption, while the employed magnetic components sometimes fail to create sufficient 
magnetic loss ability as expected $[79,104,105,116]$, which means that the upgraded reflection loss is mainly ascribed to the successful regulation of the relative complex permittivity of CPs in those cases. Compared with magnetic candidates, transition metal oxides have similar influences on the dielectric properties of CPs, and they may possess good dispersion due to the absence of magnetic attraction. As a typical semiconductor, $\mathrm{TiO}_{2}$ was reported to be a functional additive that could not only change the charge transport mechanism of PANI, but also increase the dielectric constant [119]. As a result, $\mathrm{TiO}_{2} /$ PANI composite can generally produce better dielectric loss ability and microwave absorption than pure PANI $[120,121]$. When uniform $\alpha-\mathrm{MoO}_{3}$ nanorods were utilized as the nucleation sites for PANI, small PANI nanorods with average diameter and length of about 55 and $110 \mathrm{~nm}$, respectively, would grow perpendicularly to the $\alpha-\mathrm{MoO}_{3}$ surfaces (Figure 9a), and the density of the PANI nanorods could be readily controlled by simply changing the amount of aniline in the reaction system [122]. The branched PANI $/ \alpha-\mathrm{MoO}_{3}$ heteronanostructures exhibited obviously enhanced microwave absorption in contrast to the pure PANI nanorods (Figure 9b,c), which could be attributed to their improved dielectric loss induced by additional interfacial polarization and their special structural characteristics.
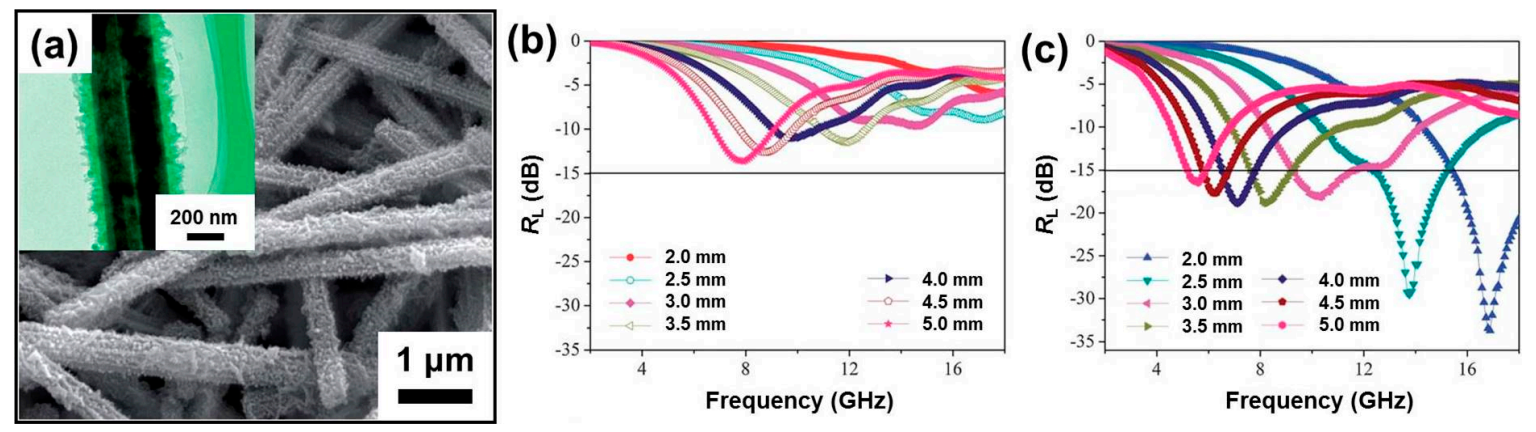

Figure 9. (a) SEM image of the branched PANI $/ \alpha-\mathrm{MoO}_{3}$ nanostructures. The inset shows a TEM image of the branched PANI / $\alpha-\mathrm{MoO}_{3}$; The $R_{\mathrm{L}}$ values of (b) the PANI nanorods and (c) the branched $\mathrm{PANI} / \alpha-\mathrm{MoO}_{3}$ nanostructures. Reprinted with permission from Reference [122].

Thanks to the universal synergetic effect between CPs and inorganic components, some transition metal oxides with good dielectric property and microwave absorption (e.g., $\mathrm{MnO}_{2}$ and $\mathrm{BaTiO}_{3}$ ) were also integrated with CPs to achieve preferable performance [123-130]. For example, $\mathrm{Hu}$ et al. obtained $\gamma-\mathrm{MnO}_{2} / \mathrm{PANI}$ nanocomposites by an in situ polymerization method, and the as-prepared $\gamma-\mathrm{MnO}_{2} / \mathrm{PANI}$ nanocomposites were found to be a characteristic dielectric medium with multiple loss mechanisms, where the resistance loss from PANI, the dielectric loss from $\mathrm{MnO}_{2}$, and polarization relaxation loss from the hybrid interface together contributed to the enhanced microwave absorption [125]. Ting et al. coated $\mathrm{BaTiO}_{3}$ particles with PANI shells, and the core-shell composites accounted for stronger and wider reflection loss than naked $\mathrm{BaTiO}_{3}$ particles in the frequency range of 2-40 GHz [129]. Saini et al. assembled ultrafine $\mathrm{BaTiO}_{3}$ nanoparticles with dodecyl benzene sulfonic acid (DBSA)-doped PANI, and made use of the resultant composite as an EM radiation shield (Figure 10). However, it was revealed that the shielding effectiveness mainly came from the absorption loss rather than reflection principle due to the good dielectric properties of the $\mathrm{BaTiO}_{3} / \mathrm{PANI}$ composite [130]. 

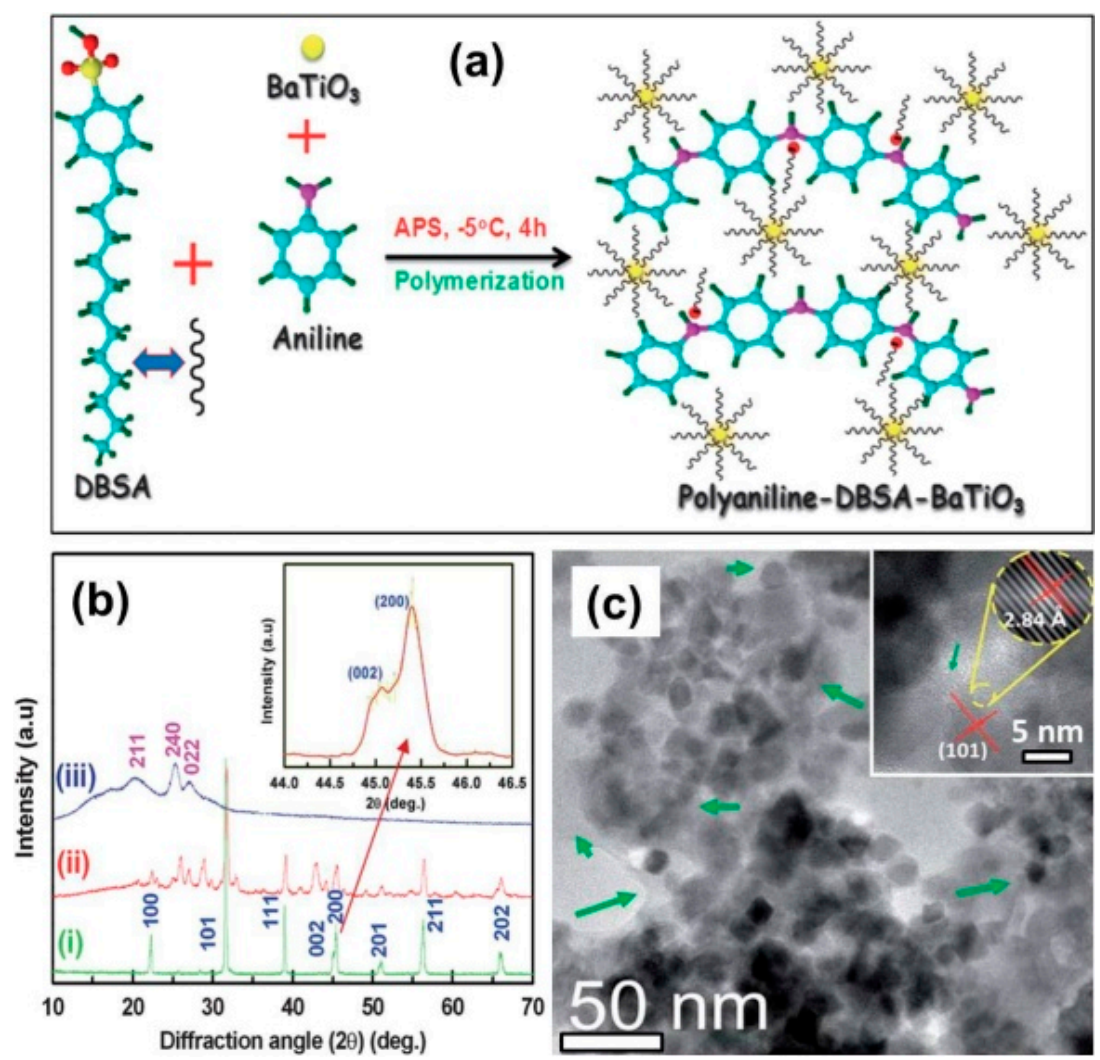

Figure 10. (a) Schematic representation on the formation of $\mathrm{PANI}_{-} \mathrm{BaTiO}_{3}$ nanocomposites by in-situ polymerization; (b) XRD patterns of (i) $\mathrm{BaTiO}_{3}$, (ii) $\mathrm{PANI}-\mathrm{BaTiO}_{3}$, and (iii) PANI showing characteristic diffraction planes; TEM image of (c) $\mathrm{PANI}_{-} \mathrm{BaTiO}_{3}$ nanocomposites (green arrows show the presence

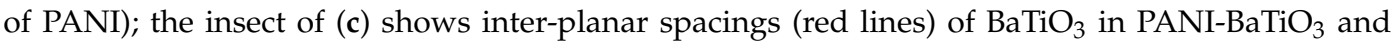
its enlarged view of lattices (encircled by dashed yellow line) Reprinted with permission from Reference [130]. DBSA: dodecyl benzene sulfonic acid.

\subsection{Carbon/CP Composites}

Carbon materials with diversified forms are a well-known dielectric loss medium and are always the most attractive candidates for microwave absorption due to their characteristic advantages. The integration of carbon materials and CPs may reinforce the dielectric loss properties and provide additional dielectric loss mechanisms (e.g., various polarizations), which will be very promising for strong absorption and wide frequency bandwidth. Furthermore, their low density is also helpful to create a new kind of lightweight MAMs. For example, when carbon black and carbon fiber are coated with a rational amount of PANI, their effective absorption for the incident EM waves will be sufficiently strengthened [131,132]. With the development of carbon science, various fine carbon materials (e.g., carbon nanotubes (CNTs) and graphene) appeared as promising MAMs and became popular carbon additives in CPs [133-147]. Sharma et al. found that a PANI-CNTs composite film could provide higher values of dielectric constant and dielectric loss factor than pure PANI film because of the interaction of PANI molecular chains with the surface functionalities of the CNTs [133]. Qiu et al. confirmed that there were apparent resonances between real parts and imaginary parts of relative complex permittivity in multi-walled CNTs (MWCNTs)/PANI composite, leading to the enhanced microwave absorption in the corresponding frequency region [135]. To obtain highly homogeneous carbon/CP composites, several novel methods and techniques were applied to control the polymerization of monomers. Zhang et al. has adopted carboxyl-functionalized MWCNT to enrich pyrrole monomers by acid-base interaction, and the polymerization of pyrrole monomers could be initiated on the surface of multi-walled CNTs rather than in a random way in the solution [138]. It was reported that the electron 
movement along the wall of CNTs-COOH was blocked in this composite, thus reducing the value of relative complex permittivity and enhancing the microwave absorption as compared with pure PPy and MWCNTs@PPy, and the effective absorption $\left(R_{\mathrm{L}}<10.0 \mathrm{~dB}\right)$ could almost cover the whole Ku band with an absorber thickness of $2.0 \mathrm{~mm}$. In addition, plasma-induced graft polymerization-i.e., plasma pretreatment of CNTs and further in situ polymerization of aniline-was also validated to be highly effective for the synthesis of hybrids of CNTs/PANI. As shown in Figure 11a-c, compared with the sample without plasma pretreatment, the one with plasma pretreatment present more uniform PANI coating on the surface of CNTs, because plasma pretreatment made more aniline grafted on the surface of CNTs by oxygen radicals which is beneficial to formation of PANI on the surface of CNTs after polymerization [139]. The conductivity of CNTs/PANI hybrids with plasma pretreatment was higher than that of CNTs/PANI hybrids without plasma pretreatment, and the CNTs/PANI with plasma pretreatment power of $50 \mathrm{~W}$ exhibited maximum value of reflection loss $(41.37 \mathrm{~dB}$ at $13.28 \mathrm{GHz}$ with a thickness of $2.0 \mathrm{~mm}$ ) (Figure 11d).
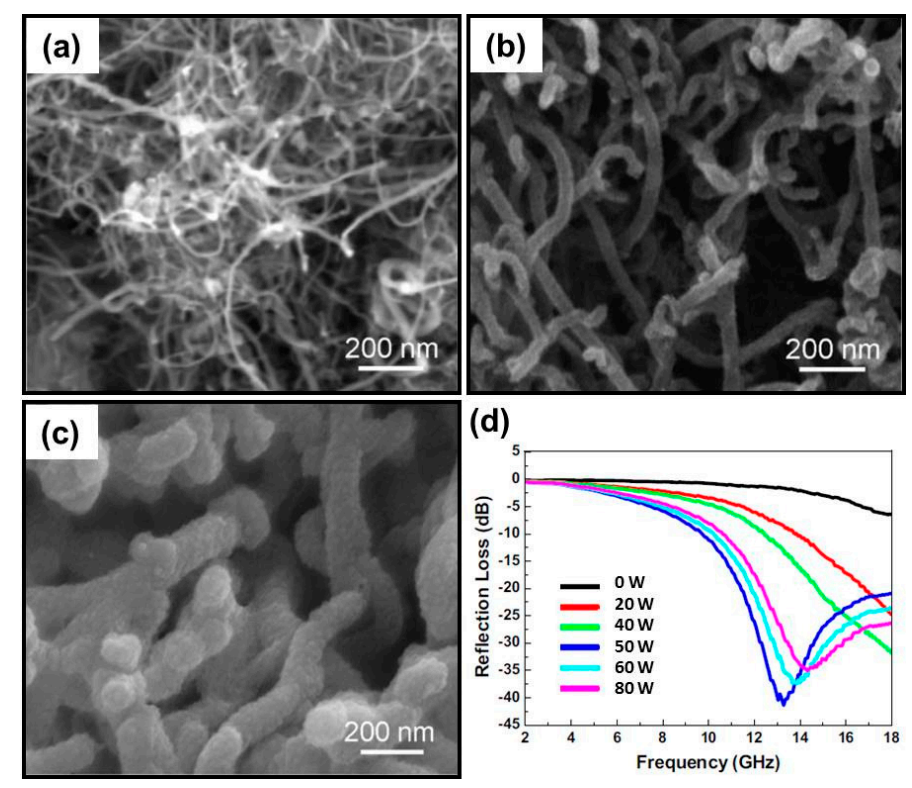

Figure 11. (a) SEM image of CNTs; (b) SEM image of CNT/PANI hybrids without plasma pretreatment; (c) SEM image of CNT/PANI hybrids with plasma pretreatment; (d) Frequency dependence of the reflection loss of CNT/PANI hybrids with different plasma pretreatment power (W) in 2-18 GHz. Reprinted with permission from Reference [139].

Compared with CNTs, graphene has better dispersion, and its unique 2D structure is endowed with excellent chemical and physical properties, including high carrier mobility, good conductivity, and large surface area. Graphene/CP composites are now residing at the frontier of functional MAMs, with immense potential for overcoming the challenges related to the performance, functionality, and durability in the field of microwave absorption. Yu et al. pioneered the fabrication of graphene/PANI composite by directing a perpendicular growth of PANI nanorods on the surface of graphene (Figure 12a,b) [140]. The presence of PANI nanorod arrays brought significantly improved microwave absorption properties, where the maximum reflection loss reached $-45.1 \mathrm{~dB}$ with a thickness of $2.5 \mathrm{~mm}$, and the absorption bandwidth with the reflection loss below $-20 \mathrm{~dB}$ was up to $10.6 \mathrm{GHz}$ (Figure 12c,d). Experimental results and theoretical simulation indicated that the enhanced EM absorption properties were attributed to the improved dielectric relaxation, the special structural characteristics, and the charge transfer between graphene and PANI nanorods. Duan et al. confirmed that the special $\pi-\pi$ interactions between graphene and PANI should be responsible for the dramatically increased microwave absorption, and first-principle calculations also revealed their mutual hybridization 
and charge transfer [141]. It is worth noting that this interaction is not limited to the system of graphene/PANI, but also works for the composites of graphene/PPy and graphene/PEDOT [145-147]. For example, Zhang et al. decorated graphene sheets with PEDOT nanofibres by non-covalent interactions, and the resultant composite showed its maximum $R_{\mathrm{L}}$ up to $-48.1 \mathrm{~dB}$ at $10.5 \mathrm{GHz}$ with a thickness of only $2 \mathrm{~mm}$ and a very broad absorption bandwidth $(5.8-15.8 \mathrm{GHz})$ over $-10 \mathrm{~dB}$ by manipulating the thickness from 1.5 to $3.0 \mathrm{~mm}$ [145]. Wu et al. yielded a 3D-reduced graphene oxide (RGO)/PEDOT composite by a solution evaporation-induced self-assembly method, and the 3D-RGO/PEDOT composite possessed good microwave absorption capabilities in both low- and high-frequency bands under different thicknesses [146].
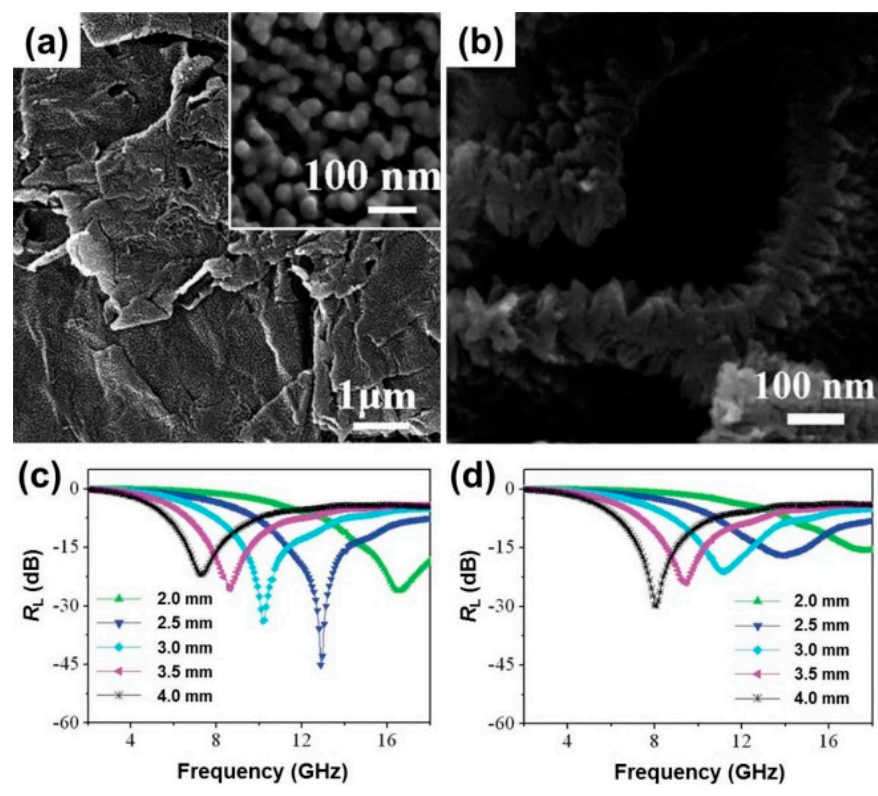

Figure 12. SEM images of graphene/PANI nanorod arrays. (a) Top-view, inset: magnified SEM image, and (b) the side-view. The reflection loss calculated for (c) the graphene/PANI nanorod arrays and (d) the PANI nanorods with thicknesses of 2-4 mm. Reprinted with permission from Reference [140].

\subsection{Multi-Compound CP-Based Composites}

As mentioned above, various binary CP-based composites have made some expected achievements in the field of microwave absorption (especially in the absorption intensity), while they still suffered from a relatively narrow EM response frequency range. In order to further boost performance, more and more interests are focusing on the construction of multi-compound $\mathrm{CP}$ composites, where each component should be introduced on purpose to further optimize the EM properties of the final composites. A literature review indicates that there are three main strategies for multi-compound CP-based composites. The first is to introduce a new magnetic component into binary magnetic CPs composites, so that the magnetic loss can be sufficiently reinforced [148-151]. Yang et al. designed a ternary $\mathrm{BaFe}_{12} \mathrm{O}_{19} / \mathrm{Y}_{3} \mathrm{Fe}_{12} \mathrm{O}_{12} /$ PANI composite, and it was found that the combination of hard magnetic ferrites $\left(\mathrm{BaFe}_{12} \mathrm{O}_{19}\right)$ and soft magnetic ferrites $\left(\mathrm{Y}_{3} \mathrm{Fe}_{12} \mathrm{O}_{12}\right)$ not only generated obvious exchange coupling behavior and magnetic loss ability, but also brought typical dielectric resonances [148]. As a result, this ternary $\mathrm{BaFe}_{12} \mathrm{O}_{19} / \mathrm{Y}_{3} \mathrm{Fe}_{12} \mathrm{O}_{12} /$ PANI composite showed much better microwave absorption than binary $\mathrm{BaFe}_{12} \mathrm{O}_{19} / \mathrm{PANI}$ composite. Although the exchange coupling behavior would disappear when the garnet-type ferrites $\left(\mathrm{Y}_{3} \mathrm{Fe}_{12} \mathrm{O}_{12}\right)$ were replaced by various spinel ferrites (e.g., $\mathrm{CoFe}_{2} \mathrm{O}_{4}, \mathrm{MnFe}_{2} \mathrm{O}_{4}, \mathrm{Ni}_{0.8} \mathrm{Zn}_{0.2} \mathrm{Fe}_{2} \mathrm{O}_{4}$ ), the ternary composites could still consume more incident EM waves [149,150].

In the second way, there are two dielectric components and one magnetic component in the multi-compound composites. Due to the high density of magnetic ferrites/metals, the improvements in 
EM properties by constantly accumulating magnetic components will be contrary to the requirements of practical applications, and thus employment of another dielectric medium becomes a more prospective mode that can maintain the specific gravity of the composites within the acceptable level. Generally, this kind of multi-compound CP-based composite is constructed on the basis of a simple magnetic composite, and the CPs will act as a shell layer and organic binder [152-163]. For example, Han et al. prepared FeNi@C@PANI nanocomposite by combining the arc-discharge process and an in situ chemical polymerization reaction. It was found that the introduction of PANI could enhance the relative complex permittivity to some extent, and pull down the density of the composite effectively. Compared with FeNi@C, the FeNi@C@PANI nanocomposite could perform similar microwave absorption with thinner absorber thickness [152]. Yang et al. also confirmed that a PPy-encapsulated nickel-coated graphite nanosheet had much better microwave absorption properties than a binary nickel-coated graphite nanosheet and a PPy-coated graphite nanosheet [155]. Bhattacharya et al. designed a ternary composite by wrapping $\mathrm{CuFe}_{10} \mathrm{Al}_{2} \mathrm{O}_{19}$ (CFA)-decorated graphene with PANI (as shown in Figure 13), and the resultant graphene/CFA/PANI composite could always create more powerful absorption than graphene/CFA in $\mathrm{X}$ band with different absorber thicknesses. The excellent microwave absorption of the prepared nanocomposites was due to the summation of good impedance matching characteristics, good complementarity of dielectric loss (due to graphene and PANI) and magnetic loss (due to CFA), good electrical conductivity, special structural characteristics, etc. [160]. In addition to various carbon substrates, $\mathrm{BaTiO}_{3}$ and $\mathrm{TiO}_{2}$ can be also utilized as the subprime dielectric medium to regulate the EM properties of ternary CP-based composites $[67,163]$.
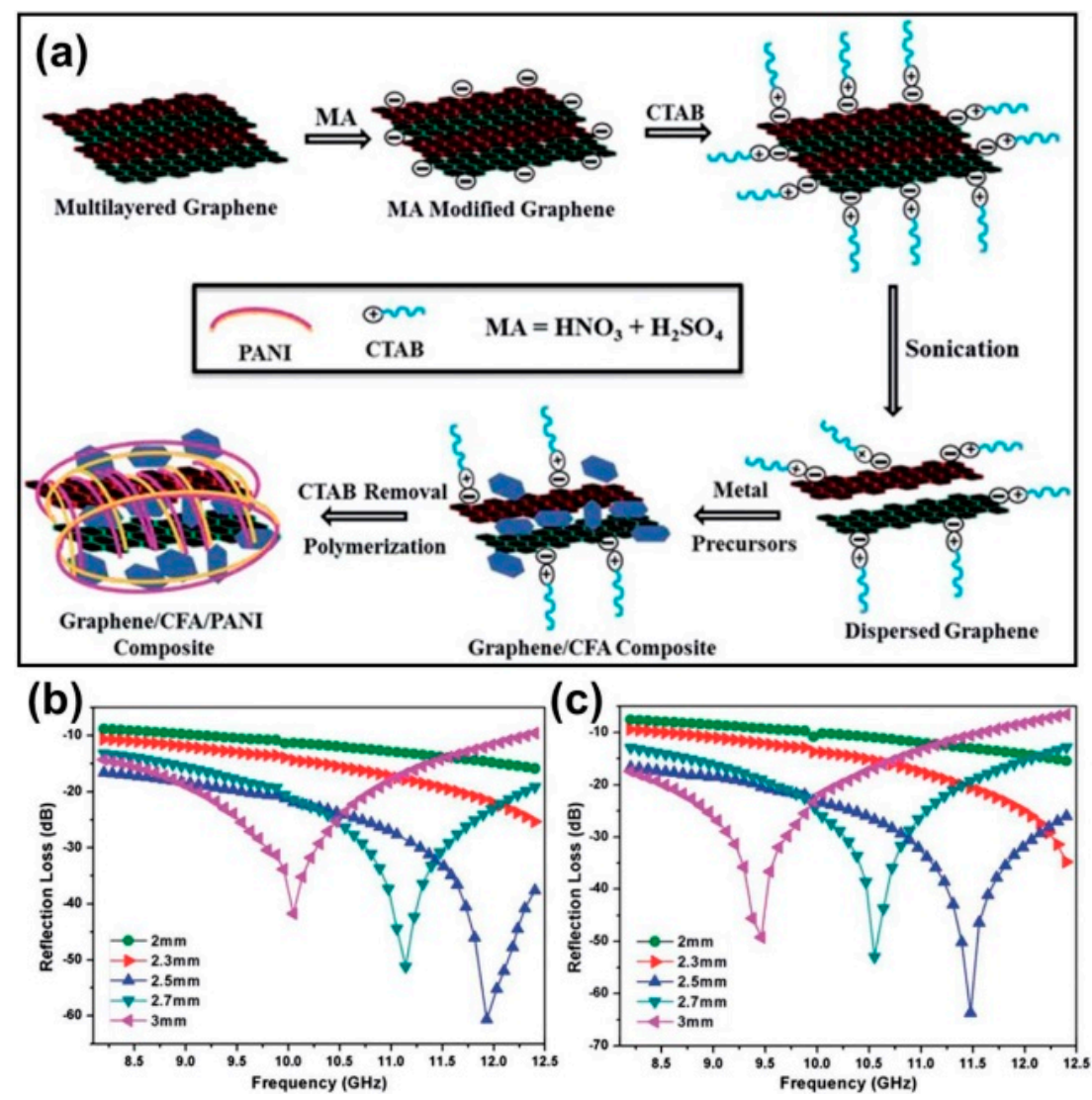

Figure 13. (a) Schematic representation of the preparation of the nanocomposites, CTAB: cetyltrimethylammonium bromide; (b) Reflection loss vs. frequency plots of graphene/CFA $\left(\mathrm{CuFe}_{10} \mathrm{Al}_{2} \mathrm{O}_{19}\right)$ and (c) graphene/CFA/PANI. Reprinted with permission from Reference [160]. 
Decorating pre-prepared carbon/CPs with magnetic nanoparticles is another alternative route to multi-compound composites with binary dielectric media [164-172]. Chen et al. and Zhang et al. deposited $\mathrm{CoFe}_{2} \mathrm{O}_{4}$ and $\mathrm{Fe}_{3} \mathrm{O}_{4}$ nanoparticles on the surfaces of expanded graphite/PANI and CNTs/PANI, respectively, and the advanced binary dielectric system and the synergetic magnetic loss were considered to be responsible for the enhanced microwave absorption [164,165]. Huang's group fabricated a series of ternary MAMs by decorating graphene/CPs with various spinel ferrite nanoparticles [166-172]. As shown in Figure 14, well-dispersed $\mathrm{Co}_{3} \mathrm{O}_{4}$ nanoparticles were located at the surface of PEDOT/graphene (PEDOT-GN), and the microwave absorption results validated that the ternary PEDOT-RGO- $\mathrm{Co}_{3} \mathrm{O}_{4}$ composite could produce better reflection loss characteristics than binary PEDOT-RGO and RGO- $\mathrm{Co}_{3} \mathrm{O}_{4}$ composites [166]. A similar phenomenon could be also found in analogous composites; e.g., graphene/PANI/ $\mathrm{NiFe}_{2} \mathrm{O}_{4}$, graphene/ PEDOT $/ \mathrm{NiFe}_{2} \mathrm{O}_{4}$, grapheme/PEDOT/CoFe $\mathrm{O}_{4}$, graphene/PANI $/ \mathrm{Fe}_{3} \mathrm{O}_{4}$, graphene/PPy $/ \mathrm{Fe}_{3} \mathrm{O}_{4}$, graphene/PANI/FeNi 3 [167-172].
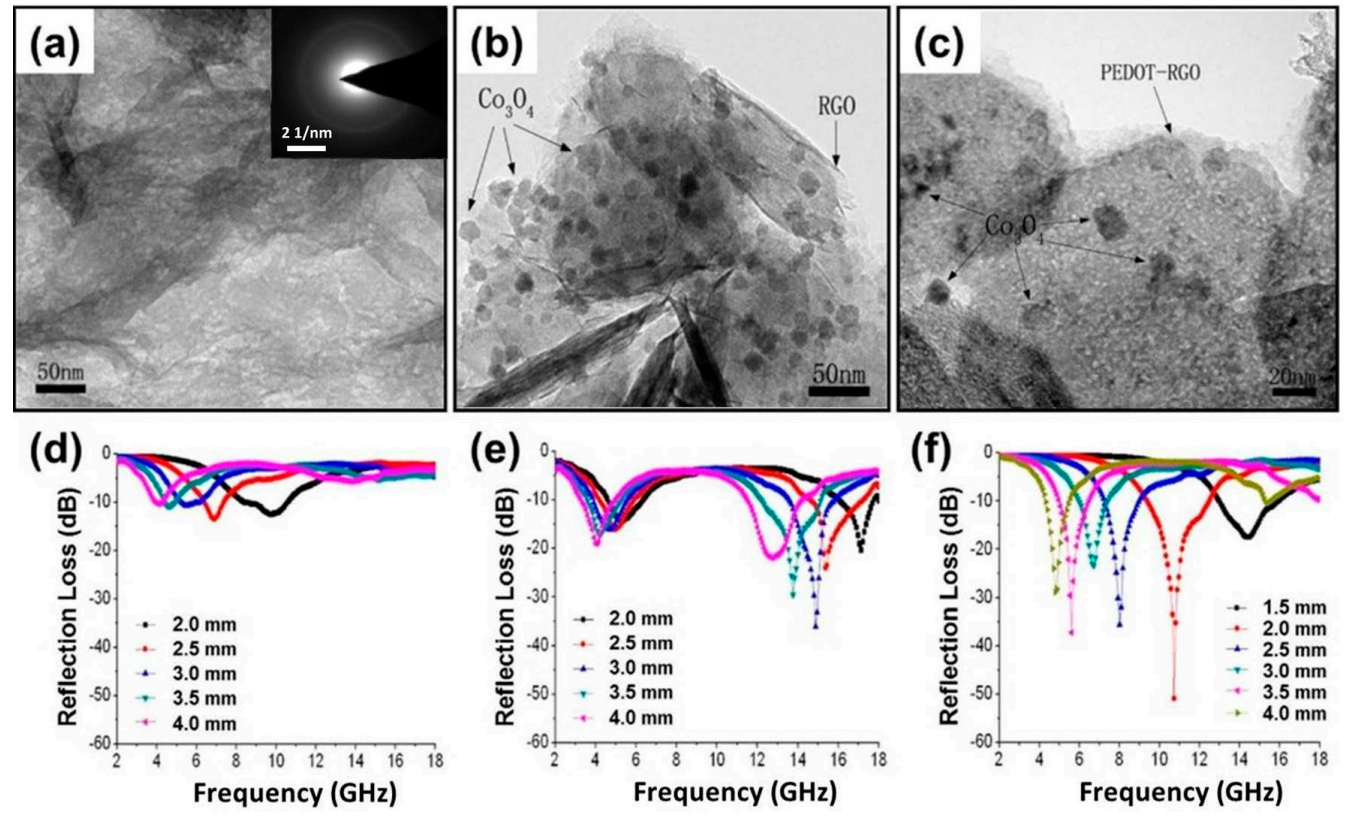

Figure 14. TEM image of (a) PEDOT-RGO (reduced graphene oxide); (b) $\mathrm{RGO}-\mathrm{Co}_{3} \mathrm{O}_{4}$; and (c) PEDOT-RGO- $\mathrm{Co}_{3} \mathrm{O}_{4}$; Reflection loss curves of (d) PEDOT-RGO; (e) $\mathrm{RGO}-\mathrm{Co}_{3} \mathrm{O}_{4}$; and (f) PEDOT-RGO- $\mathrm{Co}_{3} \mathrm{O}_{4}$. Reprinted with permission from Reference [166].

As mentioned above, well-matched characteristic impedance and good reflection loss property can be also achieved by rational manipulation of absolute dielectric loss systems [120-147], and thus the third strategy for multi-compound CP-based composites is derived from the combination of various dielectric components. For instance, Sambyal et al. blended PANI, barium strontium titanate, and expanded graphite into ternary composites with different weight ratios, and they found that the weight ratio could impact the microwave absorption of these composites greatly [173]. When the weight ratio of PANI to barium strontium titanate to expanded graphite was 1:0.1:2, the corresponding composite, PBE112, would display excellent reflection loss properties (ca. $-70 \mathrm{~dB}$ ) in the whole Ku-band. Ni et al. assembled a one-dimensional $\mathrm{CNT}_{\mathrm{BaTiO}} @ \mathrm{PANI}$ multiphase heterostructure composite via coupled sol-gel method and in situ polymerization [174]. The $\mathrm{CNT}_{\mathrm{BaTiO}} @ \mathrm{PANI}$ composite gave very broad response frequency bandwidth-less than $-10 \mathrm{~dB}$ over 7.9-15.0 GHz and less than $-20 \mathrm{~dB}$ over 10.0-15.0 GHz-with a thickness of $3.0 \mathrm{~mm}$. The excellent microwave absorption property was believed to be linked to its special structural characteristics, well-matched characteristic impedance, and interfacial polarization induced by multiple interfaces in the composite. 
More recently, several groups started to construct quaternary composites as high-performance MAMs. As shown in Figure 15, Liu et al. dispersed Au nanoparticles on the external surface of core-multishell MWCNT $/ \mathrm{Fe}_{3} \mathrm{O}_{4} / \mathrm{PANI}$ hybrid nanotubes, and Au nanoparticles therein could improve the impedance matching and function as a reflector, which induced more EM waves to be transmitted into the composite and promoted multiple reflection behaviors inside the composites [175]. As a result, the quaternary $\mathrm{MWCNT} / \mathrm{Fe}_{3} \mathrm{O}_{4} / \mathrm{PANI} / \mathrm{Au}$ hybrid composite produced better microwave absorption than the ternary $\mathrm{MWCNT} / \mathrm{Fe}_{3} \mathrm{O}_{4} / \mathrm{PANI}$ hybrid composite. In addition, quaternary graphene@ $\mathrm{Fe}_{3} \mathrm{O}_{4} @ \mathrm{SiO}_{2} @ \mathrm{PANI}$ and $\mathrm{FeNi}_{3} @ \mathrm{SiO}_{2} @ \mathrm{rGO} / \mathrm{PANI}$ composites were also reported [176,177]. Although strong absorption and wide response frequency range could be realized in these complicated composites, the specific loss mechanisms have not been explained clearly. Especially, the effects of wave-transparent $\mathrm{SiO}_{2}$ were not mentioned.

\section{(a)}
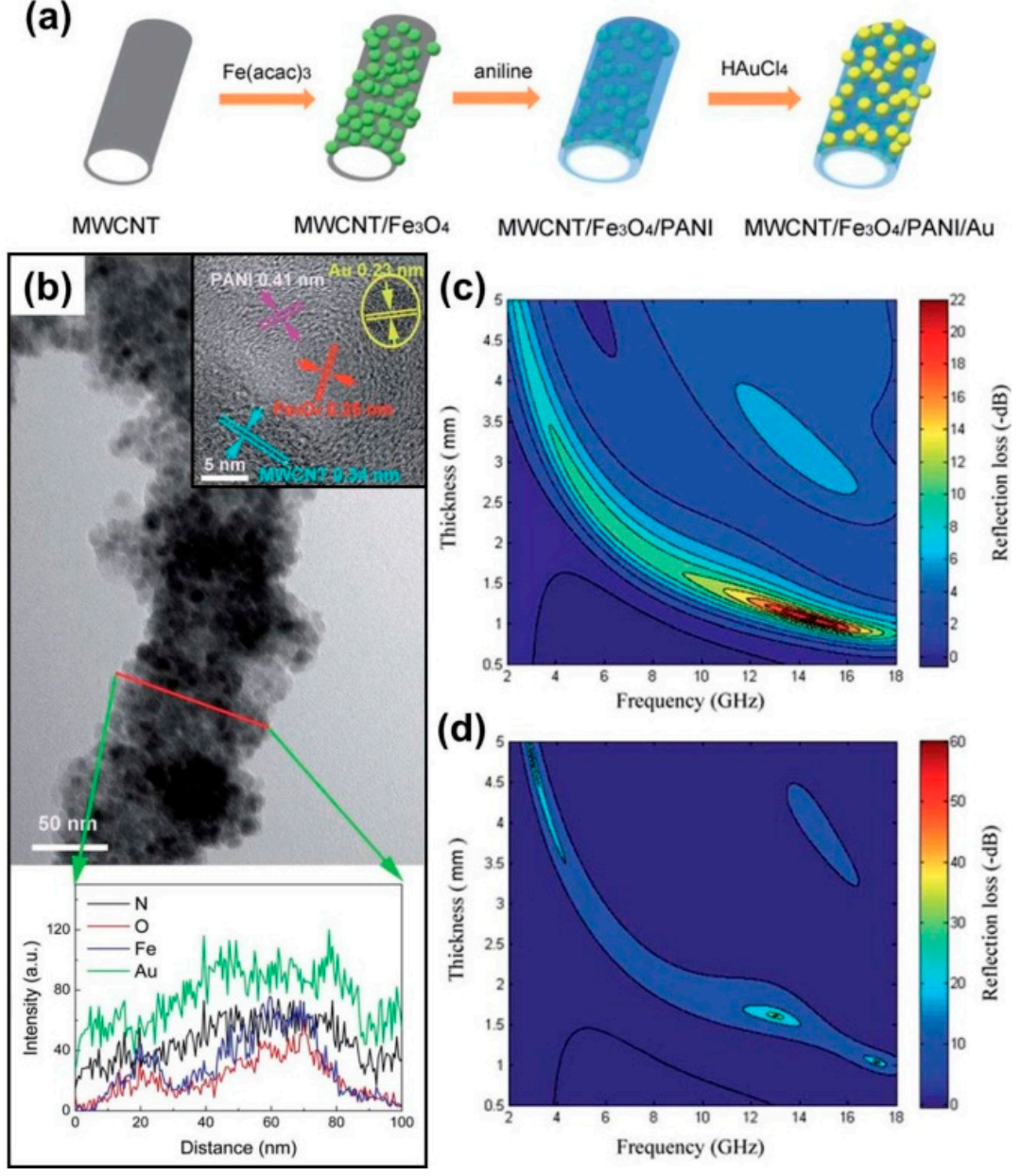

Figure 15. (a) Schematic illustration of the fabrication of $\mathrm{MWCNT} / \mathrm{Fe}_{3} \mathrm{O}_{4} / \mathrm{PANI} / \mathrm{Au}$ hybrid nanotubes. (b) TEM images of hybrid nanotubes; the bottom image shows the EDS (Energy-dispersive X-ray Spectrometer) line scan profiles of $\mathrm{N}, \mathrm{O}, \mathrm{Fe}$, and $\mathrm{Au}$; the top inset shows the HRTEM image, the yellow circle labels the gold nanoparticles. Microwave absorption characteristics of (c) ternary MWCNT/ $\mathrm{Fe}_{3} \mathrm{O}_{4} / \mathrm{PANI}$ hybrid nanotubes and (d) quaternary MWCNT/ $\mathrm{Fe}_{3} \mathrm{O}_{4} / \mathrm{PANI} / \mathrm{Au}$ hybrid nanotubes. Reprinted with permission from Reference [175].

\subsection{Multi-Layer CP-Based Composites}

In the practical applications of various MAMs, they are generally filled into some polymer matrixes to form a microwave-absorbing coating. Some theoretical analyses have predicted that optimization of the microwave absorbing coating-including the construction of multi-layer 
geometrical configuration and manipulating microstructure/morphology of MAMs—could work for the broadened absorption bandwidth [178-180], and this has been firmly supported by a series of experimental results [181-185]. Inspired by these impressive advantages, multi-layer CP-based MAMs have also been developed to pursue better performance. For example, $\mathrm{Xu}$ et al. designed double-layer MAMs with PANI as the absorbing layer and PANI $/ \mathrm{Fe}_{3} \mathrm{O}_{4}$ composite as the matching layer. When the thicknesses of the absorbing layer and the matching layer were 0.4 and $0.6 \mathrm{~mm}$, the maximum $R_{\mathrm{L}}$ would reach up to $-42 \mathrm{~dB}$ at $29.27 \mathrm{GHz}$, and the absorption bandwidth with $R_{\mathrm{L}}$ below $-10 \mathrm{~dB}$ was about $11.8 \mathrm{GHz}$ [186]. Egami et al. reinforced the microwave absorption properties of a PPy-coated non-woven fabric sheet by accumulating its stacked numbers, and they found a stack of ten sheets could consume over $95 \%$ of incident EM waves in the range of 75-110 GHz [187]. Micheli et al. synthesized multilayered MAMs with rational allocation to layer stacking of graphene nanoplatelets, carbon nanofibers, MWCNTs, and PANI, and their simulated results were consistent with the measured data, which confirmed that this heterogeneous multilayer structure was beneficial for microwave absorption [188].

\section{Comparison of Different CP-Based MAMs}

As presented above, there are many kinds of CP-based composites that can display considerable microwave absorption properties. In Table 1, we summarize the reflection loss characteristics of some representative $\mathrm{CP}$-based composites. However, one can see that these composites always perform different matched thickness and absorption frequency, and thus it is very hard to find an assessment system that can feature them comprehensively. If the assessment only focuses on maximum $R_{\mathrm{L}}$ values and effective response bandwidth, multi-compound and multi-layer CP-based composites will be preferable candidates to a certain degree, which may point to the direction of the future development of CP-based MAMs.

Table 1. Performance comparison of representative CP-based MAMs.

\begin{tabular}{|c|c|c|c|c|c|}
\hline Entry & Absorbers & $\begin{array}{l}\text { Thickness } \\
(\mathbf{m m})\end{array}$ & $\begin{array}{l}\text { Maximum } R_{\mathrm{L}} \text { and } \\
\text { Frequency }\end{array}$ & $\begin{array}{c}\text { Bandwidth over } \\
-10 \mathrm{~dB} \text { (Range, GHz) }\end{array}$ & Reference \\
\hline 1 & 3D PPy aerogel & 3.0 & $-22.5 \mathrm{~dB}$ at $12.0 \mathrm{GHz}$ & $5.0(10.0-15.0)$ & [60] \\
\hline 2 & PANI nanoparticle & 2.0 & $-18.8 \mathrm{~dB}$ at $17.2 \mathrm{GHz}$ & $3.9(14.1-18.0)$ & [62] \\
\hline 3 & $\mathrm{Fe}_{3} \mathrm{O}_{4}$ nanoparticle/PPy & 1.7 & $-35.1 \mathrm{~dB}$ at $16.7 \mathrm{GHz}$ & $2.1(15.9-18.0)$ & [79] \\
\hline 4 & $\mathrm{Fe}_{3} \mathrm{O}_{4}$ microspheres/PANI & 3.0 & $-31.3 \mathrm{~dB}$ at $9 \mathrm{GHz}$ & $2.2(7.6-9.8)$ & [86] \\
\hline 5 & $\mathrm{BaFe}_{12} \mathrm{O}_{19} /$ PANI & 2.0 & $-20.0 \mathrm{~dB}$ at $14.5 \mathrm{GHz}$ & $4.0(12.8-16.8)$ & {$[95]$} \\
\hline 6 & $\mathrm{Ni} / \mathrm{PANI}$ & 1.0 & $-23.0 \mathrm{~dB}$ at $17.8 \mathrm{GHz}$ & $2.5(15.5-18.0)$ & [118] \\
\hline 7 & $\alpha-\mathrm{MoO}_{3} / \mathrm{PANI}$ & 2.0 & $-34.0 \mathrm{~dB}$ at $16.8 \mathrm{GHz}$ & $2.8(15.2-18.0)$ & [122] \\
\hline 8 & MCNT-COOH/PPy & 3.5 & $-16.0 \mathrm{~dB}$ at $11.5 \mathrm{GHz}$ & $4.5(9.5-14.0)$ & [138] \\
\hline 9 & Graphene/PANI & 2.5 & $-45.1 \mathrm{~dB}$ at $12.9 \mathrm{GHz}$ & $5.4(10.6-16.0)$ & [140] \\
\hline 10 & $0.9 \mathrm{BaFe}_{12} \mathrm{O}_{19} / 0.1 \mathrm{Y}_{3} \mathrm{Fe}_{5} \mathrm{O}_{12} / \mathrm{PANI}$ & 2.9 & $-40.8 \mathrm{~dB}$ at $9.9 \mathrm{GHz}$ & $5.5(6.8-12.3)$ & [148] \\
\hline 11 & Graphene/CuFe ${ }_{10} \mathrm{~A}_{12} \mathrm{O}_{19} /$ PANI & 2.5 & $-63.6 \mathrm{~dB}$ at $11.5 \mathrm{GHz}$ & $4.5(8.0-12.5)$ & [160] \\
\hline 12 & $\mathrm{NiFe}_{2} \mathrm{O}_{4} /$ graphene/PEDOT & 2.5 & $-50.5 \mathrm{~dB}$ at $12.5 \mathrm{GHz}$ & $5.3(11.0-16.3)$ & [168] \\
\hline 13 & Graphene $/ \mathrm{Fe}_{3} \mathrm{O}_{4} / \mathrm{SiO}_{2} /$ PANI & 2.5 & $-40.7 \mathrm{~dB}$ at $12.5 \mathrm{GHz}$ & $5.8(10.5-16.3)$ & [176] \\
\hline 14 & $\mathrm{Fe}_{3} \mathrm{O}_{4}$-PANI layer/PANI layer & 1.0 & $-42.0 \mathrm{~dB}$ at $29.27 \mathrm{GHz}$ & $11.8(25.5-37.3)$ & [186] \\
\hline
\end{tabular}

\section{Conclusions and Outlook}

This review highlighted the recent developments related to conjugated polymer-based composites as promising microwave absorbing materials (MAMs). Some studies reported that rational design on the microstructure of conjugated polymers (CPs) was an effective strategy to regulate their EM properties and improve the matching of characteristic impedance, and as a result, some CPs with unique microstructures—such as PANI microrods, PANI nanoparticles, multi-shelled PEDOT hollow microspheres, and highly uniform core-shell PPy@PANI—displayed significantly enhanced microwave absorption as compared with their conventional individual components. There have also been more tremendous interests in constructing heterogeneous $\mathrm{CP}$-based composites with various magnetic ferrites, magnetic metal, transition metal oxides, and diversified carbon materials for microwave 
absorption application. The integration of CPs and these inorganic additives could generally create obvious synergetic effects and complementary behaviors, as well as more loss mechanisms (e.g., various polarization relaxations), which contribute to the microwave absorption performance greatly. To further upgrade the attenuation for incident EM waves, the EM properties of CP-based composites could be optimized by incorporating secondary magnetic components or dielectric components. Therefore, ternary and quaternary CP-based composites are making breakthroughs and are becoming a popular approach for high-performance MAMs. In addition, CP-based composites also share their applications in multi-layer MAMs, which were more suitable for practical microwave absorption. The rational arrangement in multi-layer MAMs made great contribution to broadened response bandwidth.

Although significant progress has been made in these CP-based composites, a gap to real industrial applications still exists, as current composites cannot fulfill the particular demands for MAMs, which means that more efforts are still required in this field. First, the frequency range upon the effective absorption is still less than the expected bandwidth, so that accumulating the absorber thicknesses or constructing multi-layer configuration is extensively adopted to broaden the response frequency range in most research cases. As mentioned above, rational design on the microstructure may reinforce the microwave absorption of pure CPs, while this motivation is rarely referred for CP-based composites. Constructing multi-compound composites with unique microstructure (e.g., hollow, yolk-shell, smaller particle size)—which can intensify the reflection and scattering behaviors of EM waves inside MAMs-will be a promising and challenging task to produce desirable microwave absorption performance. Second, many studies intently pursue the enhancement of microwave absorption regardless of other assessment criteria. Actually, low density and loading amount are very important in practical applications, especially in the field of aeronautics and astronautics. Therefore, with the premise of comparable functionality, the employment of ultra-light additives is quite meaningful for various CP-based composites. Third, some CPs and magnetic components usually suffer from some rigorous conditions and long-time application, and thus the stability and lifetime of CP-based composites should also be worth considering. In summary, CP-based composites exhibit their potential as a promising kind of MAMs, although they are at an initial stage from the related research. It is believed that novel CP-based composites with ideal compositions and optimal microstructures will present a bright future in the field of microwave absorption.

Acknowledgments: We thank the financial support from NSFC (No. 21371039, 21571043, 21676065) and Natural Science Foundation of Heilongjiang Province (B201405).

Conflicts of Interest: The authors declare no conflict of interest.

\section{References}

1. Zhang, Y.; Huang, Y.; Zhang, T.F.; Chang, H.C.; Xiao, P.S.; Chen, H.H.; Huang, Z.Y.; Chen, Y.S. Broadband and tunable high-performance microwave absorption of an ultralight and highly compressible graphene foam. Adv. Mater. 2015, 27, 2049-2053. [CrossRef] [PubMed]

2. Lu, M.M.; Cao, M.S.; Chen, Y.H.; Cao, W.Q.; Liu, J.; Shi, H.L.; Zhang, D.Q.; Wang, W.Z.; Yuan, J. Multiscale assembly of grape-like ferroferric oxide and carbon nanotubes: A smart absorber prototype varying temperature to tune intensities. ACS Appl. Mater. Interfaces 2015, 7, 19408-19415. [CrossRef] [PubMed]

3. Sun, H.; Che, R.C.; You, X.; Jiang, Y.S.; Yang, Z.B.; Deng, J.; Qiu, L.B.; Peng, H.S. Cross-stacking aligned carbon-nanotube films to tune microwave absorption frequencies and increase absorption intensities. Adv. Mater. 2014, 26, 8120-8125. [CrossRef] [PubMed]

4. Qiang, R.; Du, Y.C.; Zhao, H.T.; Wang, Y.; Tian, C.H.; Li, Z.G.; Han, X.J.; Xu, P. Metal organic framework-derived $\mathrm{Fe} / \mathrm{C}$ nanocubes toward efficient microwave absorption. J. Mater. Chem. A 2015, 3, 13426-13434. [CrossRef]

5. Chung, D.D.L. Electromagnetic interference shielding effectiveness of carbon materials. Carbon 2001, 39, 279-285. [CrossRef]

6. Tong, X.C. Advanced Materials and Design for Electromagnetic Interference; Taylor \& Francis: Boca Raton, FL, USA, 2009. 
7. Qin, F.; Brosseau, C. A review and analysis of microwave absorption in polymer composites filled with carbonaceous particles. J. Appl. Phys. 2012, 111, 061301. [CrossRef]

8. Zhang, X.J.; Wang, G.S.; Cao, W.Q.; Wei, Y.Z.; Liang, J.F.; Guo, L.; Cao, M.S. Enhanced microwave absorption property of reduced graphene oxide (RGO)- $\mathrm{MnFe}_{2} \mathrm{O}_{4}$ nanocomposites and polyvinylidene fluoride. ACS Appl. Mater. Interfaces 2014, 6, 7471-7478. [CrossRef] [PubMed]

9. Zhang, Y.; Huang, Y.; Chen, H.H.; Huang, Z.Y.; Yang, Y.; Xiao, P.S.; Zhou, Y.; Chen, Y.S. Composition and structure control of ultralight graphene foam for high-performance microwave absorption. Carbon 2016, 105, 438-447. [CrossRef]

10. Li, X.H.; Feng, J.; Du, Y.P.; Bai, J.T.; Fan, H.M.; Zhang, H.L.; Peng, Y.; Li, F.S. One-pot synthesis of $\mathrm{CoFe}_{2} \mathrm{O}_{4}$ /graphene oxide hybrids and their conversion into $\mathrm{FeCo} /$ graphene hybrids for lightweight and highly efficient microwave absorber. J. Mater. Chem. A 2015, 3, 5535-5546. [CrossRef]

11. Sun, G.; Dong, B.; Cao, M.; Wei, B.; Hu, C. Hierarchical dendrite-like magnetic materials of $\mathrm{Fe}_{3} \mathrm{O}_{4}, \gamma-\mathrm{Fe}_{2} \mathrm{O}_{3}$, and Fe with high performance of microwave absorption. Chem. Mater. 2011, 23, 1587-1593. [CrossRef]

12. Wen, S.L.; Liu, Y.; Zhao, X.C.; Cheng, J.W.; Li, H. Synthesis, dual-nonlinear magnetic resonance and microwave absorption properties of nanosheet hierarchical cobalt particles. Phys. Chem. Chem. Phys. 2014, 16, 18333-18340. [CrossRef] [PubMed]

13. Wang, C.; Han, X.J.; Xu, P.; Wang, J.Y.; Du, Y.C.; Wang, X.H.; Qin, W.; Zhang, T. Controlled synthesis of hierarchical nickel and morphology-dependent electromagnetic properties. J. Phys. Chem. C 2010, 114, 3196-3203. [CrossRef]

14. Li, X.A.; Zhang, B.; Ju, C.H.; Han, X.J.; Du, Y.C.; Xu, P. Morphology-controlled synthesis and electromagnetic properties of porous $\mathrm{fe}_{3} \mathrm{O}_{4}$ nanostructures from iron alkoxide precursors. J. Phys. Chem. C 2011, 115, 12350-12357. [CrossRef]

15. Ghasemi, A.; Hossienpour, A.; Morisako, A.; Saatchi, A.; Salehi, M. Electromagnetic properties and microwave absorbing characteristics of doped barium hexaferrite. J. Magn. Magn. Mater. 2006, 302, 429-435. [CrossRef]

16. Wu, R.B.; Zhou, K.; Yang, Z.H.; Qian, X.K.; Wei, J.; Liu, L.; Huang, Y.Z.; Kong, L.B.; Wang, L.Y. Molten-salt-mediated synthesis of $\mathrm{SiC}$ nanowires for microwave absorption applications. CrystEngComm 2013, 15, 570-576. [CrossRef]

17. Zhu, Y.F.; Zhang, L.; Natsuki, T.; Fu, Y.Q.; Ni, Q.Q. Facile Synthesis of $\mathrm{BaTiO}_{3}$ nanotubes and their microwave absorption properties. ACS Appl. Mater. Interfaces 2012, 4, 2101-2106. [CrossRef] [PubMed]

18. Wang, Y.; Du, Y.C.; Qiang, R.; Tian, C.H.; Xu, P.; Han, X.J. Interfacially engineered sandwich-like rGO/carbon microspheres/rGO composite as an efficient and durable microwave absorber. Adv. Mater. Interfaces 2016, 3, 1500684. [CrossRef]

19. Zhuo, R.F.; Qiao, L.; Feng, H.T.; Chen, J.T.; Yan, D.; Wu, Z.G.; Yan, P.X. Microwave absorption properties and the isotropic antenna mechanism of ZnO nanotrees. J. Appl. Phys. 2008, 104, 094101. [CrossRef]

20. Burroughes, J.H.; Bradley, D.D.C.; Brown, A.R.; Marks, R.N.; Mackay, K.; Friend, R.H.; Burns, P.L.; Holmes, A.B. Light-emitting diodes based on conjugated polymers. Nature 1990, 347, 539-541. [CrossRef]

21. Grimsdale, A.C.; Chan, K.L.; Martin, R.E.; Jokisz, P.G.; Holmes, A.B. Synthesis of light-emitting conjugated polymers for applications in electroluminescent devices. Chem. Rev. 2009, 109, 897-1091. [CrossRef] [PubMed]

22. Yip, H.L.; Jen, A.K.Y. Recent advances in solution-processed interfacial materials for efficient and stable polymer solar cells. Energy Environ. Sci. 2012, 5, 5994-6011. [CrossRef]

23. Li, G.; Zhu, R.; Yang, Y. Polymer solar cells. Nat. Photonics 2012, 6, 153-161. [CrossRef]

24. Allard, S.; Forster, M.; Souharce, B.; Thiem, H.; Scherf, U. Organic semiconductors for solution-processable field-effect transistors (OFETs). Angew. Chem. Int. Ed. 2008, 47, 4070-4098. [CrossRef] [PubMed]

25. Wang, C.L.; Dong, H.L.; Hu, W.P.; Liu, Y.Q.; Zhu, D.B. Semiconducting $\pi$-conjugated systems in field-effect transistors: A material odyssey of organic electronics. Chem. Rev. 2011, 112, 2208-2267. [CrossRef] [PubMed]

26. Guan, W.J.; Zhou, W.J.; Lu, J.; Lu, C. Luminescent films for chemo-and biosensing. Chem. Soc. Rev. 2015, 44, 6981-7009. [CrossRef] [PubMed]

27. Liu, B.; Bazan, G.C. Homogeneous fluorescence-based DNA detection with water-soluble conjugated polymers. Chem. Mater. 2004, 16, 4467-4476. [CrossRef]

28. Pron, A.; Rannou, P. Processible conjugated polymers: From organic semiconductors to organic metals and superconductors. Prog. Polym. Sci. 2002, 27, 135-190. [CrossRef] 
29. Yoshino, K.; Tabata, M.; Kaneto, K.; Ohsawa, T. Application and characteristics of conducting polymer as radiation shielding material. Jpn. J. Appl. Phys. 1985, 24, L693-L695. [CrossRef]

30. Taka, T. EMI shielding measurements on poly(3-octyl thiophene) blends. Synth. Met. 1991, 41, 1177-1180. [CrossRef]

31. Chandrasekhar, P.; Naishadham, K. Broadband microwave absorption and shielding properties of a poly(aniline). Synth. Met. 1999, 105, 115-120. [CrossRef]

32. Tian, C.H.; Du, Y.C.; Xu, P.; Qiang, R.; Wang, Y.; Ding, D.; Xue, J.L.; Ma, J.; Zhao, H.T.; Han, X.J. Constructing uniform core-shell PPy@PANI composites with tunable shell thickness toward enhancement in microwave absorption. ACS Appl. Mater. Interfaces 2015, 7, 20090-20099. [CrossRef] [PubMed]

33. Wang, Y. Microwave absorbing materials based on polyaniline composites: A review. Int. J. Mater. Res. 2014, 105, 3-12. [CrossRef]

34. Pang, R.; Hu, X.J.; Zhou, S.Y.; Sun, C.H.; Yan, J.; Sun, X.M.; Xiao, S.Z.; Chen, P. Preparation of multi-shelled conductive polymer hollow microspheres by using $\mathrm{Fe}_{3} \mathrm{O}_{4}$ hollow spheres as sacrificial templates. Chem. Commun. 2014, 50, 12493-12496. [CrossRef] [PubMed]

35. McDowell, A.J.; Hubing, T.H. Analysis and comparison of plane wave shielding effectiveness decompositions. IEEE Trans. Electromagn. C 2014, 56, 1711-1714. [CrossRef]

36. Chen, N.; Mu, G.H.; Pan, X.F.; Gan, K.K.; Gu, M.Y. Microwave absorption properties of $\mathrm{SrFe}_{12} \mathrm{O}_{19} / \mathrm{ZnFe}_{2} \mathrm{O}_{4}$ composite powders. Mat. Sci. Eng. B Adv. 2007, 139, 256-260. [CrossRef]

37. Kim, S.S.; Jo, S.B.; Gueon, K.I.; Choi, K.K.; Kim, J.M.; Churn, K.S. Complex permeability and permittivity and microwave absorption of ferrite-rubber composite at X-band frequencies. IEEE Trans. Magn. 1991, 27, 5462-5464. [CrossRef]

38. Lu, M.M.; Cao, W.Q.; Shi, H.L.; Fang, X.Y.; Yang, J.; Hou, Z.L.; Jin, H.B.; Wang, W.Z.; Yuan, J.; Cao, M.S. Multi-wall carbon nanotubes decorated with ZnO nanocrystals: Mild solution-process synthesis and highly efficient microwave absorption properties at elevated temperature. J. Mater. Chem. A 2014, 2, 10540-10547. [CrossRef]

39. Wen, B.; Cao, M.S.; Hou, Z.L.; Song, W.L.; Zhang, L.; Lu, M.M.; Jin, H.B.; Fang, X.Y.; Wang, W.Z.; Yuan, J. Temperature dependent microwave attenuation behavior for carbon-nanotube/silica composites. Carbon 2013, 65, 124-139. [CrossRef]

40. Kittel, C. Introduction to Solid State Physics, 8th ed.; John Wiley \& Sons, Inc.: New York, NY, USA, 2005.

41. Ramo, S.; Whinnery, J.R.; Duzer, T.V. Fields and Waves in Communication Electronics, 3rd ed.; John Wiley \& Sons, Inc.: New York, NY, USA, 1994.

42. Ohlan, A.; Singh, K.; Chandra, A.; Dhawan, S.K. Microwave absorption behavior of core-shell structured poly(3,4-ethylenedioxy thiophene)-barium ferrite nanocomposites. ACS Appl. Mater. Interfaces 2010, 2, 927-933. [CrossRef] [PubMed]

43. Zhao, B.; Zhao, W.Y.; Shao, G.; Fan, B.B.; Zhang, R. Morphology-control synthesis of a core-shell structured $\mathrm{NiCu}$ alloy with tunable electromagnetic-wave absorption capabilities. ACS Appl. Mater. Interfaces 2015, 7, 12951-12960. [CrossRef] [PubMed]

44. He, S.; Lu, C.; Wang, G.S.; Wang, J.W.; Guo, H.Y.; Guo, L. Synthesis and growth mechanism of white-fungus-like nickel sulfide microspheres, and their application in polymer composites with enhanced microwave-absorption properties. ChemPlusChem 2014, 79, 569-576. [CrossRef]

45. Cole, K.S.; Cole, R.H. Dispersion and absorption in dielectrics I. Alternating current characteristics. J. Chem. Phys. 1941, 9, 341-351. [CrossRef]

46. Ding, D.; Wang, Y.; Li, X.D.; Qiang, R.; Xu, P.; Chu, W.L.; Han, X.J.; Du, Y.C. Rational design of core-shell Co@C microspheres for high-performance microwave absorption. Carbon 2017, 111, 722-732. [CrossRef]

47. Wu, M.; Zhang, Y.D.; Hui, S.; Xiao, T.D.; Ge, S.; Hines, W.A.; Budnick, J.I.; Taylor, G.W. Microwave magnetic properties of $\mathrm{Co}_{50} /\left(\mathrm{SiO}_{2}\right)_{50}$ nanoparticles. Appl. Phys. Lett. 2002, 80, 4404-4406. [CrossRef]

48. Kittel, C. On the theory of ferromagnetic resonance absorption. Phys. Rev. 1948, 73, 155-161. [CrossRef]

49. Lu, B.; Dong, X.L.; Huang, H.; Zhang, X.F.; Zhu, X.G.; Lei, J.P.; Sun, J.P. Microwave absorption properties of the core/shell-type iron and nickel nanoparticles. J. Magn. Magn. Mater. 2008, 320, 1106-1111. [CrossRef]

50. Liao, S.B. Ferromagnetic Physics; Science Press: Beijing, China, 1992.

51. Kim, S.S.; Kim, S.T.; Yoon, Y.C.; Lee, K.S. Magnetic, dielectric, and microwave absorbing properties of iron particles dispersed in rubber matrix in gigahertz frequencies. J. Appl. Phys. 2005, 97, 10F905. [CrossRef] 
52. Gao, B.; Qiao, L.; Wang, J.B.; Liu, Q.F.; Li, F.S.; Feng, J.; Xue, D.S. Microwave absorption properties of the Ni nanowires composite. J. Phys. D Appl. Phys. 2008, 41, 235005. [CrossRef]

53. Lv, R.T.; Cao, A.Y.; Kang, F.Y.; Wang, W.X.; Wei, J.Q.; Gu, J.L.; Wang, K.L.; Wu, D.H. Single-crystalline permalloy nanowires in carbon nanotubes: Enhanced encapsulation and magnetization. J. Phys. Chem. C 2007, 111, 11475-11479. [CrossRef]

54. Vinoy, K.J.; Jha, R.M. Radar Absorbing Materials: From Theory to Design and Characterization; Kluwer: Boston, MA, USA, 1996.

55. Du, Y.C.; Liu, W.W.; Qiang, R.; Wang, Y.; Han, X.J.; Ma, J.; Xu, P. Shell thickness-dependent microwave absorption of core-shell $\mathrm{Fe}_{3} \mathrm{O}_{4} @ \mathrm{C}$ composites. ACS Appl. Mater. Interfaces 2014, 6, 12997-13006. [CrossRef] [PubMed]

56. Song, W.L.; Cao, M.S.; Fan, L.Z.; Lu, M.M.; Li, Y.; Wang, C.Y.; Ju, H.F. Highly ordered porous carbon/wax composites for effective electromagnetic attenuation and shielding. Carbon 2014, 77, 130-142. [CrossRef]

57. Ma, Z.; Zhang, Y.; Cao, C.T.; Yuan, J.; Liu, Q.F.; Wang, J.B. Attractive microwave absorption and the impedance match effect in zinc oxide and carbonyl iron composite. Phys. B 2011, 406, 4620-4624. [CrossRef]

58. Zhang, X.; Zhu, J.H.; Haldolaarachchige, N.; Ryu, J.; Young, D.P.; Wei, S.Y.; Guo, Z.H. Synthetic process engineered polyaniline nanostructures with tunable morphology and physical properties. Polymer 2012, 53, 2109-2120. [CrossRef]

59. Sun, Y.Y.; Guo, G.Z.; Yang, B.H.; Zhou, X.; Cui, H.Y.; Liu, Y.Q.; Zhao, G.Z. Synthesis of polyaniline microrods with high microwave absorption behaviours. Micro Nano Lett. 2010, 5, 313-316. [CrossRef]

60. Xie, A.; Wu, F.; Sun, M.X.; Dai, X.Q.; Xu, Z.H.; Qiu, Y.Y.; Wang, Y.; Wang, M.Y. Self-assembled ultralight three-dimensional polypyrrole aerogel for effective electromagnetic absorption. Appl. Phys. Lett. 2015, 106, 222902. [CrossRef]

61. Wu, F.; Sun, M.X.; Jiang, W.C.; Zhang, K.; Xie, A.M.; Wang, Y.; Wang, M.Y. A self-assembly method for the fabrication of a three-dimensional (3d) polypyrrole (PPy)/poly(3,4-Ethylenedioxythiophene) (PEDOT) hybrid composite with excellent absorption performance against electromagnetic pollution. J. Mater. Chem. C 2016, 4, 82-88. [CrossRef]

62. Zhang, P.; Han, X.J.; Kang, L.L.; Qiang, R.; Liu, W.W.; Du, Y.C. Synthesis and characterization of polyaniline nanoparticles with enhanced microwave absorption. RSC Adv. 2013, 3, 12694-12701. [CrossRef]

63. Lee, S.P.; Chen, Y.J.; Ho, C.M.; Chang, C.P.; Hong, Y.S. A study on synthesis and characterization of the core-shell materials of $\mathrm{Mn}_{1-x} \mathrm{Zn}_{x} \mathrm{Fe}_{2} \mathrm{O}_{4}$-Polyaniline. Mater. Sci. Eng. B Adv. 2007, 143, 1-6. [CrossRef]

64. Han, X.; Wang, Y.S. Studies on the synthesis and microwave absorption properties of $\mathrm{Fe}_{3} \mathrm{O}_{4} /$ polyaniline FGM. Phys. Scr. 2007, 129, 335-339. [CrossRef]

65. Wang, Z.Z.; Bi, H.; Liu, J.; Sun, T.; Wu, X.L. Magnetic and microwave absorbing properties of polyaniline $/ \gamma-\mathrm{Fe}_{2} \mathrm{O}_{3}$ nanocomposite. J. Magn. Magn. Mater. 2008, 320, 2132-3139. [CrossRef]

66. Yang, C.M.; Li, H.Y.; Xiong, D.B.; Cao, Z.Y. Hollow polyaniline $/ \mathrm{Fe}_{3} \mathrm{O}_{4}$ microsphere composites: Preparation, characterization, and applications in microwave absorption. React. Funct. Polym. 2009, 69, 137-144. [CrossRef]

67. Phang, S.W.; Tadokoro, M.; Watanabe, J.; Kuramoto, N. Effect of $\mathrm{Fe}_{3} \mathrm{O}_{4}$ and $\mathrm{TiO}_{2}$ addition on the microwave absorption property of polyaniline micro/nanocomposites. Polym. Adv. Technol. 2009, 20, 550-557. [CrossRef]

68. Yang, C.H.; Du, J.J.; Peng, Q.; Qiao, R.R.; Chen, W.; Xu, C.L.; SHuai, Z.G.; Gao, M.Y. Polyaniline $/ \mathrm{Fe}_{3} \mathrm{O}_{4}$ nanoparticle composite: Synthesis and reaction mechanism. J. Phys. Chem. B 2009, 113, 5052-5058. [CrossRef] [PubMed]

69. Ma, R.T.; Zhao, H.T.; Zhang, G. Preparation, characterization and microwave absorption properties of polyaniline $/ \mathrm{Co}_{0.5} \mathrm{Zn}_{0.5} \mathrm{Fe}_{2} \mathrm{O}_{4}$ nanocomposite. Mater. Res. Bull. 2010, 45, 1064-1068. [CrossRef]

70. Gandhi, N.; Singh, K.; Ohlan, A.; Singh, D.P.; Dhawan, S.K. Thermal, dielectric and microwave absorption properties of polyaniline-CoFe $\mathrm{O}_{4}$ nanocomposites. Compos. Sci. Technol. 2011, 71, 1754-1760. [CrossRef]

71. Belaabed, B.; Wojkiewicz, J.L.; Lamouri, S.; Kamchi, N.E.; Lasri, T. Synthesis and characterization of hybrid conducting composites based on polyaniline/magnetite fillers with improved microwave absorption properties. J. Alloy. Compd. 2012, 527, 137-144. [CrossRef]

72. Hosseini, S.H.; Asadnia, A. Synthesis, characterization, and microwave-absorbing properties of polypyrrole/ $\mathrm{MnFe}_{2} \mathrm{O}_{4}$ nanocomposite. J. Nanomater. 2012, 2012, 198973. [CrossRef] 
73. Zhou, W.C.; Hu, X.J.; Zhou, S.Y.; Yan, J.; Sun, C.H.; Chen, P. Facile route to controlled iron oxides/poly(3,4-ethylenedioxythiophene) nanocomposites and microwave absorbing properties. Compos. Sci. Technol. 2013, 87, 14-21. [CrossRef]

74. Zhu, Y.F.; Ni, Q.Q.; Fu, Y.Q.; Natsuki, T. Synthesis and microwave absorption properties of electromagnetic functionalized $\mathrm{Fe}_{3} \mathrm{O}_{4}$-polyaniline hollow sphere nanocomposites produced by electrostatic self-assembly. J. Nanopart. Res. 2013, 15, 1988. [CrossRef] [PubMed]

75. Wang, C.P.; Shen, Y.H.; Wang, X.F.; Zhang, H.; Xie, A.J. Synthesis of novel NiZn-Ferrite/polyaniline nanocomposites and their microwave absorption properties. Mat. Sci. Semicond. Prog. 2013, 16, 77-82. [CrossRef]

76. Wang, M.; Ji, G.B.; Zhang, B.S.; Tang, D.M.; Yang, Y.; Du, Y.W. Controlled synthesis and microwave absorption properties of $\mathrm{Ni}_{0.6} \mathrm{Zn}_{0.4} \mathrm{Fe}_{2} \mathrm{O}_{4} /$ PANI composite via an in-situ polymerization process. J. Magn. Magn. Mater. 2015, 377, 52-58. [CrossRef]

77. Li, Z.T.; Ye, M.Q.; Han, A.J.; Du, H. Preparation, characterization and microwave absorption properties of $\mathrm{NiFe}_{2} \mathrm{O}_{4}$ and its composites with conductive polymer. J. Mater. Sci. Mater. Electron. 2016, 27, 1031-1043. [CrossRef]

78. Sun, Y.P.; Xiao, F.; Liu, X.G.; Feng, C.; Jin, C.G. Preparation and electromagnetic wave absorption properties of core-shell structured $\mathrm{Fe}_{3} \mathrm{O}_{4}$-polyaniline nanoparticles. RSC Adv. 2013, 3, 22554-22559. [CrossRef]

79. Li, Y.B.; Chen, G.; Li, Q.H.; Qiu, G.Z.; Liu, X.H. Facile synthesis, magnetic and microwave absorption properties of $\mathrm{Fe}_{3} \mathrm{O}_{4}$ /polypyrrole core/shell nanocomposite. J. Alloy Compd. 2011, 509, 4104-4107. [CrossRef]

80. Nakamura, T. Snoek's limit in high-frequency permeability of polycrystalline Ni-Zn, Mg-Zn, and Ni-Zn-Cu spinel ferrites. J. Appl. Phys. 2000, 88, 348-353. [CrossRef]

81. Tong, G.X.; Wu, W.H.; Guan, J.G.; Qian, H.S.; Yuan, J.H.; Li, W. Synthesis and characterization of nanosized urchin-like $\alpha-\mathrm{Fe}_{2} \mathrm{O}_{3}$ and $\mathrm{Fe}_{3} \mathrm{O}_{4}$ : Microwave electromagnetic and absorbing properties. J. Alloy Compd. 2011, 509, 4320-4326. [CrossRef]

82. Li, Q.F.; Li, Y.F.; Li, X.; Chen, S.L.; Zhang, S.D.; Wang, J.Z.; Hou, C. A facile synthesis of superparamagnetic hybrid hollow nanospheres based on monodisperse nickel-zinc ferrite/polyethylene glycol and their electromagnetic, microwave absorbing properties. J. Alloy Compd. 2014, 608, 35-43. [CrossRef]

83. Wang, F.L.; Liu, J.R.; Kong, J.; Zhang, Z.J.; Wang, X.C.; Itoh, M.; Machida, K.I. Template free synthesis and electromagnetic wave absorption properties of monodispersed hollow magnetite nano-spheres. J. Mater. Chem. 2011, 21, 4314-4320. [CrossRef]

84. Ji, R.L.; Cao, C.B.; Chen, Z.; Zhai, H.Z.; Bai, J. Solvothermal synthesis of $\mathrm{Co}_{x} \mathrm{Fe}_{3-x} \mathrm{O}_{4}$ spheres and their microwave absorption properties. J. Mater. Chem. C 2014, 2, 5944-5953. [CrossRef]

85. Gu, X.; Zhu, W.M.; Jia, C.J.; Zhao, R.; Schmidt, W.; Wang, Y.Q. Synthesis and microwave absorbing properties of highly ordered mesoporous crystalline $\mathrm{NiFe}_{2} \mathrm{O}_{4}$. Chem. Commun. 2011, 47, 5337-5339. [CrossRef] [PubMed]

86. Cui, C.K.; Du, Y.C.; Li, T.H.; Zheng, X.Y.; Wang, X.H.; Han, X.J.; Xu, P. Synthesis of electromagnetic functionalized $\mathrm{Fe}_{3} \mathrm{O}_{4}$ microspheres/polyaniline composites by two-step oxidative polymerization. J. Phys. Chem. B 2012, 116, 9523-9531. [CrossRef] [PubMed]

87. Zhang, B.; Du, Y.C.; Zhang, P.; Zhao, H.T.; Kang, L.L.; Han, X.J.; Xu, P. Microwave absorption enhancement of $\mathrm{Fe}_{3} \mathrm{O}_{4}$ / polyaniline core/shell hybrid microspheres with controlled shell thickness. J. Appl. Polym. Sci. 2013, 130, 1909-1916. [CrossRef]

88. Zhou, W.C.; Hu, X.J.; Bai, X.X.; Zhou, S.Y.; Sun, C.H.; Yan, J.; Chen, P. Synthesis and electromagnetic, microwave absorbing properties of core-shell $\mathrm{Fe}_{3} \mathrm{O}_{4}$-poly(3, 4-ethylenedioxythiophene) microspheres. ACS Appl. Mater. Interfaces 2011, 3, 3839-3845. [CrossRef] [PubMed]

89. Qiao, M.T.; Lei, X.F.; Ma, Y.; Tian, L.D.; Su, K.H.; Zhang, Q.Y. Well-defined core-shell $\mathrm{Fe}_{3} \mathrm{O}_{4} @$ polypyrrole composite microspheres with tunable shell thickness: Synthesis and their superior microwave absorption performance in the Ku band. Ind. Eng. Chem. Res. 2016, 55, 6263-6275. [CrossRef]

90. Truedson, J.R.; McKinstry, K.D.; Karim, R.; Patton, C.E. Effective linewidth due to conductivity losses in barium ferrite at $10 \mathrm{GHz}$. IEEE Trans. Magn. 1992, 28, 3309-3311. [CrossRef]

91. Cho, H.S.; Kim, S.S. M-hexaferrites with planar magnetic anisotropy and their application to high-frequency microwave absorbers. IEEE Trans. Magn. 1999, 35, 3151-3153.

92. Pullar, R.C. Hexagonal ferrites: A review of the synthesis, properties and applications of hexaferrite ceramics. Prog. Mater. Sci. 2012, 57, 1191-1334. [CrossRef] 
93. Meshram, M.R.; Agrawal, N.K.; Sinha, B.; Misra, P.S. Characterization of M-type barium hexagonal ferrite-based wide band microwave absorber. J. Magn. Magn. Mater. 2004, 271, 207-214. [CrossRef]

94. Iqbal, M.J.; Ashiq, M.N.; Gul, I.H. Physical, electrical and dielectric properties of Ca-substituted strontium hexaferrite $\left(\mathrm{SrFe}_{12} \mathrm{O}_{19}\right)$ nanoparticles synthesized by co-precipitation method. J. Magn. Magn. Mater. 2010, 322, 1720-1726. [CrossRef]

95. Xu, P.; Han, X.J.; Jiang, J.J.; Wang, X.H.; Li, X.D.; Wen, A.H. Synthesis and characterization of novel coralloid polyaniline $/ \mathrm{BaFe}_{12} \mathrm{O}_{19}$ nanocomposites. J. Phys. Chem. C 2007, 111, 12603-12608. [CrossRef]

96. Xu, P.; Han, X.J.; Wang, C.; Zhao, H.T.; Wang, J.Y.; Wang, X.H.; Zhang, B. Synthesis of electromagnetic functionalized barium ferrite nanoparticles embedded in polypyrrole. J. Phys. Chem. B 2008, 112, 2775-2781. [CrossRef] [PubMed]

97. Jiang, J.; Ai, L.H.; Qin, D.B.; Liu, H.; Li, L.C. Preparation and characterization of electromagnetic functionalized polyaniline/ $\mathrm{BaFe}_{12} \mathrm{O}_{19}$ composites. Synth. Met. 2009, 159, 695-699. [CrossRef]

98. Tang, X.; Yang, Y.G. Surface modification of M-Ba-Ferrite powders by polyaniline: Towards improving microwave electromagnetic response. Appl. Surf. Sci. 2009, 255, 9381-9385. [CrossRef]

99. Yang, C.C.; Gung, Y.J.; Hung, W.C.; Ting, T.H.; Wu, K.H. Infrared and microwave absorbing properties of $\mathrm{BaTiO} 3 /$ polyaniline and $\mathrm{BaFe}_{12} \mathrm{O}_{19}$ /polyaniline composites. Compos. Sci. Technol. 2010, 70, 466-471. [CrossRef]

100. Yuan, C.L.; Hong, Y.S. Microwave adsorption of core-shell structure polyaniline $/ \mathrm{SrFe}_{12} \mathrm{O}_{19}$ composites. J. Mater. Sci. 2010, 45, 3470-3476. [CrossRef]

101. Li, Y.X.; Zhang, H.W.; Liu, Y.L.; Wen, Q.Y.; Li, J. Rod-shaped polyaniline-barium ferrite nanocomposite: Preparation, characterization and properties. Nanotechnology 2008, 19, 105605. [CrossRef] [PubMed]

102. Ma, L.; Gan, M.Y.; Tang, J.H.; Li, Z.T.; Zheng, J.Y.; Zhang, J.; Xie, S.; Yin, H.; Shen, X.Y.; Hu, J.L.; et al. Preparation and characterization of chiral polyaniline/barium hexaferrite composite with enhanced microwave absorbing properties. J. Alloy Compd. 2014, 593, 24-29. [CrossRef]

103. Zhao, H.T.; Du, Y.C.; Kang, L.L.; Xu, P.; Du, L.; Sun, Z.H.; Han, X.J. Precursor-directed synthesis of quasi-spherical barium ferrite particles with good dispersion and magnetic properties. CrystEngComm 2013, 15, 808-815. [CrossRef]

104. Liu, J.L.; Zhang, J.; Li, Y.Q.; Zhang, M. Microwave absorbing properties of barium hexa-ferrite/polyaniline core-shell nano-composites with controlled shell thickness. Mater. Chem. Phys. 2015, 163, 470-477. [CrossRef]

105. Du, L.; Du, Y.C.; Li, Y.; Wang, J.Y.; Wang, C.; Wang, X.H.; Xu, P.; Han, X.J. Surfactant-assisted solvothermal synthesis of $\mathrm{Ba}(\mathrm{CoTi})_{x} \mathrm{Fe}_{12-2 x} \mathrm{O}_{19}$ nanoparticles and enhancement in microwave absorption properties of polyaniline. J. Phys. Chem. C 2010, 114, 19600-19606. [CrossRef]

106. Li, L.C.; Xiang, C.; Liang, X.X.; Hao, B. $\mathrm{Zn}_{0.6} \mathrm{Cu}_{0.4} \mathrm{Cr}_{0.5} \mathrm{Fe}_{1.46} \mathrm{Sm}_{0.04} \mathrm{O}_{4}$ ferrite and its nanocomposites with polyaniline and polypyrrole: Preparation and electromagnetic properties. Synth. Met. 2010, 160, $28-34$. [CrossRef]

107. Abbas, S.M.; Dixit, A.K.; Chatterjee, R.; Goel, T.C. Complex permittivity, complex permeability and microwave absorption properties of ferrite-polymer composites. J. Magn. Magn. Mater. 2007, 309, $20-24$. [CrossRef]

108. Kuo, H.M.; Hsui, T.F.; Tuo, Y.S.; Yuan, C.L. Microwave adsorption of core-shell structured $\mathrm{Sr}(\mathrm{MnTi})_{x} \mathrm{Fe}_{12-2 x} \mathrm{O}_{19} /$ PANI composites. J. Mater. Sci. 2012, 47, 2264-2270. [CrossRef]

109. Tadjarodi, A.; Kerdari, H.; Imani, M. $\mathrm{Ba}_{0.69} \mathrm{Sr}_{0.17} \mathrm{Cd}_{0.07} \mathrm{Zn}_{0.07} \mathrm{Fe}_{12} \mathrm{O}_{19}$ nanostrucutres/conducting polyaniline nanocomposites; synthesis, characterization and microwave absorption performance. J. Alloy Compd. 2013, 554, 284-292. [CrossRef]

110. Guo, F.Y.; Li, R.Q.; Xu, J.J.; Zou, L.C.; Gan, S.C. Electromagnetic properties and microwave absorption enhancement of $\mathrm{Ba}_{0.85} \mathrm{RE}_{0.15} \mathrm{Co}_{2} \mathrm{Fe}_{16} \mathrm{O}_{27}$-polyaniline composites: $\mathrm{RE}=\mathrm{Gd}, \mathrm{Tb}, \mathrm{Ho}$. Colloid Polym. Sci. 2014, 292, 2173-2183. [CrossRef]

111. Guo, F.Y.; Zi, W.W.; Ji, G.J.; Zou, L.C.; Gan, S.C. Polyaniline containing W-type hexaferrite composites for microwave absorption in high-frequency applications. J. Polym. Res. 2015, 22, 48. [CrossRef]

112. Luo, J.H.; Xu, Y.; Mao, H.K. Magnetic and microwave absorption properties of rare earth ions $\left(\mathrm{Sm}^{3+}, \mathrm{Er}^{3+}\right)$ doped strontium ferrite and its nanocomposites with polypyrrole. J. Magn. Magn. Mater. 2015, 381, 365-371. [CrossRef] 
113. Fan, X.A.; Guan, J.G.; Wang, W.; Tong, G.X. Morphology evolution, magnetic and microwave absorption properties of nano/submicrometre iron particles obtained at different reduced temperatures. J. Phys. D Appl. Phys. 2009, 42, 075006. [CrossRef]

114. Qiang, R.; Du, Y.C.; Chen, D.T.; Ma, W.J.; Wang, Y.; Xu, P.; Ma, J.; Zhao, H.T.; Han, X.J. Electromagnetic functionalized $\mathrm{Co} / \mathrm{C}$ composites by in situ pyrolysis of metal-organic frameworks (ZIF-67). J. Alloy Compd. 2016, 681, 384-393. [CrossRef]

115. Dong, X.L.; Zhang, X.F.; Huang, H.; Zuo, F. Enhanced microwave absorption in Ni/polyaniline nanocomposites by dual dielectric relaxations. Appl. Phys. Lett. 2008, 92, 013127. [CrossRef]

116. Xu, P.; Han, X.J.; Wang, C.; Zhou, D.H.; Lv, Z.S.; Wen, A.H.; Wang, X.H.; Zhang, B. Synthesis of electromagnetic functionalized nickel/polypyrrole core/shell composites. J. Phys. Chem. B 2008, 112, 10443-10448. [CrossRef] [PubMed]

117. Luo, J.H.; Gao, D.D. Synthesis and microwave absorption properties of PPy/Co nanocomposites. J. Magn. Magn. Mater. 2014, 368, 82-86. [CrossRef]

118. Han, D.D.; Xiao, N.R.; Hu, H.; Liu, B.; Song, G.X.; Yan, H. Ultrasmall superparamagnetic Ni nanoparticles embedded in polyaniline as a lightweight and thin microwave absorber. RSC Adv. 2015, 5, 66667-66673. [CrossRef]

119. Dey, A.; De, S.; De, A.; De, S.K. Characterization and dielectric properties of polyaniline- $\mathrm{TiO}_{2}$ nanocomposites. Nanotechnology 2004, 15, 1277-1283. [CrossRef]

120. Phang, S.W.; Tadokoro, M.; Watanabe, J.; Kuramot, N. Microwave absorption behaviors of polyaniline nanocomposites containing $\mathrm{TiO}_{2}$ nanoparticles. Curr. Appl. Phys. 2008, 8, 391-394. [CrossRef]

121. Li, Q.L.; Zhang, C.R.; Li, J.Q. Photocatalysis and wave-absorbing properties of polyaniline/TiO2 microbelts composite by in situ polymerization method. Appl. Surf. Sci. 2010, 257, 944-948. [CrossRef]

122. Wang, Q.S.; Lei, Z.Y.; Chen, Y.J.; Ouyang, Q.Y.; Gao, P.; Qi, L.H.; Zhu, C.L.; Zhang, J.Z. Branched polyaniline/molybdenum oxide organic/inorganic heteronanostructures: Synthesis and electromagnetic absorption properties. J. Mater. Chem. A 2013, 1, 11795-11801. [CrossRef]

123. Duan, Y.P.; Pang, H.F.; Zhang, Y.H.; Chen, J.L.; Wang, T.M. Morphology-controlled synthesis and microwave absorption properties of $\beta-\mathrm{MnO}_{2}$ microncube with rectangular pyramid. Mater. Charact. 2016, 112, $206-212$. [CrossRef]

124. Yang, J.; Zhang, J.; Liang, C.Y.; Wang, M.; Zhao, P.F.; Liu, M.M.; Liu, J.W.; Che, R.C. Ultrathin BaTiO 3 nanowires with high aspect ratio: A simple one-step hydrothermal synthesis and their strong microwave absorption. ACS Appl. Mater. Interfaces 2013, 5, 7146-7151. [CrossRef] [PubMed]

125. Hu, J.J.; Duan, Y.P.; Zhang, J.; Jing, H.; Liu, S.H.; Li, W.P. $\gamma-\mathrm{MnO}_{2} /$ polyaniline composites: Preparation, characterization, and applications in microwave absorption. Physica B 2011, 406, 1950-1955.

126. Abbas, S.M.; Dixit, A.K.; Chatterjee, R.; Geol, T.C. Complex permittivity and microwave absorption properties of $\mathrm{BaTiO}_{3}$-polyaniline composite. Mater. Sci. Eng. B Adv. 2005, 123, 167-171. [CrossRef]

127. Jing, H.X.; Li, Q.L.; Ye, Y.; Guo, Z.W.; Yang, X.F. Preparation and microwave adsorption properties of core-shell structured barium titanate/polyaniline composite. J. Magn. Magn. Mater. 2013, 332, 10-14.

128. Zhu, Y.F.; Fu, Y.Q.; Natsuki, T.; Ni, Q.Q. Fabrication and microwave absorption properties of $\mathrm{BaTiO}_{3}$ nanotube/polyaniline hybrid nanomaterials. Polym. Compos. 2013, 34, 265-273. [CrossRef]

129. Ting, T.H.; Wu, K.H. Synthesis and electromagnetic wave-absorbing properties of $\mathrm{BaTiO}_{3} /$ polyaniline structured composites in 2-40 GHz. J. Polym. Res. 2013, 20, 127. [CrossRef]

130. Saini, P.; Arora, M.; Gupta, G.; Gupta, B.K.; Singh, V.N.; Choudhary, V. High permittivity polyaniline-barium titanate nanocomposites with excellent electromagnetic interference shielding response. Nanoscale 2013, 5, 4330-4336. [CrossRef] [PubMed]

131. Wu, K.H.; Ting, T.H.; Wang, G.P.; Ho, W.D.; Shih, C.C. Effect of carbon black content on electrical and microwave absorbing properties of polyaniline/carbon black nanocomposites. Polym. Degrad. Stab. 2008, 93, 483-488. [CrossRef]

132. Joon, S.; Kumar, R.; Singh, A.P.; Shukla, R.; Dhawan, R.S. Fabrication and microwave shielding properties of free standing polyaniline-carbon fiber thin sheets. Mater. Chem. Phys. 2015, 160, 87-95. [CrossRef]

133. Sharma, B.K.; Khare, N.; Sharma, R.; Dhawan, S.K.; Vankar, V.D.; Gupta, H.C. Dielectric behavior of polyaniline-CNTs composite in microwave region. Compos. Sci. Technol. 2009, 69, 1932-1935. [CrossRef]

134. Ting, T.H.; Jau, Y.N.; Yu, R.P. Microwave absorbing properties of polyaniline/multi-walled carbon nanotube composites with various polyaniline contents. Appl. Surf. Sci. 2012, 258, 3184-3190. [CrossRef] 
135. Qiu, H.; Wang, J.; Qi, S.H.; He, Z.; Fan, X.; Dong, Y.Q. Microwave absorbing properties of multi-walled carbon nanotubes/polyaniline nanocomposites. J. Mater. Sci. Mater. Electron. 2015, 26, 564-570. [CrossRef]

136. Farukh, M.; Singh, A.P.; Dhawan, S.K. Enhanced electromagnetic shielding behavior of multi-walled carbon nanotube entrenched poly(3,4-ethylenedioxythiophene) nanocomposites. Compos. Sci. Technol. 2015, 114, 94-102. [CrossRef]

137. Bai, X.X.; Hu, X.J.; Zhou, S.Y.; Li, L.F.; Rohwerder, M. Controllable synthesis of leaflet-like poly(3,4-ethylenedioxythiophene)/single-walled carbon nanotube composites with microwave absorbing property. Compos. Sci. Technol. 2015, 110, 166-175. [CrossRef]

138. Zhang, K.; Xie, A.M.; Wu, F.; Jiang, W.C.; Wang, M.Y.; Dong, W. Carboxyl multiwalled carbon nanotubes modified polypyrrole(PPy) aerogel for enhanced electromagnetic absorption. Mater. Res. Express 2016, 3, 055008. [CrossRef]

139. Cheng, J.Y.; Zhao, B.; Zheng, S.Y.; Yang, J.H.; Zhang, D.Q.; Cao, M.S. Enhanced microwave absorption performance of polyaniline-coated CNT hybrids by plasma-induced graft polymerization. Appl. Phys. A 2015, 119, 379-386. [CrossRef]

140. Yu, H.L.; Wang, T.S.; Wen, B.; Lu, M.M.; Xu, Z.; Zhu, C.L.; Chen, Y.J.; Xue, X.Y.; Sun, C.W.; Cao, M.S. Graphene/polyaniline nanorod arrays: Synthesis and excellent electromagnetic absorption properties. J. Mater. Chem. 2012, 22, 21679-21685. [CrossRef]

141. Duan, Y.P.; Liu, J.; Zhang, Y.H.; Wang, T.M. First-principles calculations of graphene-based polyaniline nano-hybrids for insight of electromagnetic properties and electronic structures. RSC Adv. 2016, 6, 73915-73923. [CrossRef]

142. Liu, P.B.; Huang, Y. Decoration of reduced graphene oxide with polyaniline film and their enhanced microwave absorption properties. J. Polym. Res. 2014, 21, 430. [CrossRef]

143. Chen, X.N.; Meng, F.C.; Zhou, Z.W.; Tian, X.; Shan, L.M.; Zhu, S.B.; Xu, X.L.; Jiang, M.; Wang, L.; Hui, D.; et al. One-step synthesis of graphene/polyaniline hybrids by in situ intercalation polymerization and their electromagnetic properties. Nanoscale 2014, 6, 8140-8148. [CrossRef] [PubMed]

144. Wang, Y.; Xu, X.M.; Zhang, W.Z. Synthesis and high-performance microwave absorption of graphene foam/polyaniline nanorods. Mater. Lett. 2016, 165, 71-74. [CrossRef]

145. Zhang, X.; Huang, Y.; Li, P.B. Enhanced electromagnetic wave absorption properties of poly(3,4-ethylenedioxythiophene) nanofiber-decorated graphene sheets by non-covalent interactions. Nano-Micro Lett. 2016, 8, 131-136. [CrossRef]

146. Wu, F.; Wang, Y.; Wang, M.Y. Using organic solvent absorption as a self-assembly method to synthesize three-dimensional (3D) reduced graphene oxide (RGO)/poly(3,4-ethylenedioxythiophene) (PEDOT) architecture and its electromagnetic absorption properties. RSC Adv. 2014, 4, 49780-49782. [CrossRef]

147. Chen, X.N.; Chen, J.J.; Meng, F.B.; Shan, L.M.; Jiang, M.; Xu, X.L.; Lu, J.; Wang, Y.; Zhou, Z.W. Hierarchical composites of polypyrrole/graphene oxide synthesized by in situ intercalation polymerization for high efficiency and broadband responses of electromagnetic absorption. Compos. Sci. Technol. 2016, 127, 71-78. [CrossRef]

148. Yang, H.B.; Ye, T.; Lin, Y.; Liu, M. Exchange coupling behavior and microwave absorbing property of the hard/soft $\left(\mathrm{BaFe}_{12} \mathrm{O}_{19} / \mathrm{Y}_{3} \mathrm{Fe}_{5} \mathrm{O}_{12}\right)$ ferrites based on polyaniline. Synth. Met. 2015, 210, 245-250. [CrossRef]

149. Yang, H.B.; Ye, T.; Lin, Y.; Liu, M. Excellent microwave absorption property of ternary composite: polyaniline- $\mathrm{BaFe}_{12} \mathrm{O}_{19}-\mathrm{CoFe}_{2} \mathrm{O}_{4}$ powders. J. Alloy Compd. 2015, 653, 135-139. [CrossRef]

150. Hosseini, S.H.; Moghimi, A.; Moloudi, M. Magnetic, conductive, and microwave absorption properties of polythiophene nanofibers layered on $\mathrm{MnFe}_{2} \mathrm{O}_{4} / \mathrm{Fe}_{3} \mathrm{O}_{4}$ core-shell structures. Mater. Sci. Semicond. Prog. 2014, 24, 272-277. [CrossRef]

151. Wang, Y.; Huang, Y.; Wang, Q.F.; He, Q.; Chen, L. Preparation and electromagnetic properties of polyaniline(polypyrrole)- $\mathrm{BaFe}_{12} \mathrm{O}_{19} / \mathrm{Ni}_{0.8} \mathrm{Zn}_{0.2} \mathrm{Fe}_{2} \mathrm{O}_{4}$ ferrite nanocomposites. Appl. Surf. Sci. 2012, 259, 486-493. [CrossRef]

152. Han, D.D.; Xiao, N.R.; Hu, H.; Liu, B.; Song, G.X.; Yan, H. A promising broadband and thin microwave absorber based on ternary FeNi@C@polyaniline nanocomposites. RSC Adv. 2015, 5, 97944-97950. [CrossRef]

153. Liu, X.G.; Or, S.W.; Leung, C.M.; Ho, S.L. Core/shell/shell-structured nickel/carbon/polyaniline nanocapsules with large absorbing bandwidth and absorber thickness range. J. Appl. Phys. 2014, 115, 17A507. [CrossRef] 
154. Xu, Y.; Luo, J.H.; Yao, W.; Xu, J.G.; Li, T. Preparation of reduced graphene oxide/flake carbonyl iron powders/polyaniline composites and their enhanced microwave absorption properties. J. Alloy Compd. 2015, 636, 310-316. [CrossRef]

155. Yang, Y.Q.; Qi, S.H.; Wang, J.N. Preparation and microwave absorbing properties of nickel-coated graphite nanosheet with pyrrole via in situ polymerization. J. Alloy Compd. 2012, 520, 114-121. [CrossRef]

156. Fang, J.Y.; Chen, Z.; Wei, W.; Li, Y.X.; Liu, T.; Liu, Z.; Yue, X.G.; Jiang, Z.H. A carbon fiber based three-phase heterostructure composite $\mathrm{CF} / \mathrm{Co}_{0.2} \mathrm{Fe}_{2.8} \mathrm{O}_{4} /$ PANI as an efficient electromagnetic wave absorber in the $\mathrm{Ku}$ band. RSC Adv. 2015, 5, 50024-50032. [CrossRef]

157. Cao, M.S.; Yang, J.; Song, W.L.; Zhang, D.Q.; Wen, B.; Jin, H.B.; Hou, Z.L.; Yuan, J. Ferroferric oxide/multiwalled carbon nanotube vs. polyaniline/ferroferric oxide/multiwalled carbon nanotube multiheterostructures for highly effective microwave absorption. ACS Appl. Mater. Interfaces 2012, 4, 6949-6956. [CrossRef] [PubMed]

158. Zhao, J.; Lin, J.P.; Xiao, J.P.; Fan, H.L. Synthesis and electromagnetic, microwave absorbing properties of polyaniline/graphene oxide $/ \mathrm{Fe}_{3} \mathrm{O}_{4}$ nanocomposites. $R S C$ Adv. 2015, 5, 19345-19352. [CrossRef]

159. Luo, J.H.; Xu, Y.; Yao, W.; Jiang, C.F.; Xu, J.G. Synthesis and microwave absorption properties of reduced graphene oxide-magnetic porous nanospheres-polyaniline composites. Compos. Sci. Technol. 2015, 117, 315-321. [CrossRef]

160. Bhattacharya, P.; Dhibar, S.; Hatui, G.; Mandal, A.; Das, T.; Das, C.K. Graphene decorated with hexagonal shaped M-Type ferrite and polyaniline wrapper: A potential candidate for electromagnetic wave absorbing and energy storage device applications. RSC Adv. 2014, 4, 17039-17053. [CrossRef]

161. Yang, R.B.; Reddy, P.M.; Chang, C.J.; Chen, P.A.; Chen, J.K.; Chang, C.C. Synthesis and characterization of $\mathrm{Fe}_{3} \mathrm{O}_{4} /$ Polypyrrole/carbon nanotube composites with tunable microwave absorption properties: Role of carbon nanotube and polypyrrole content. Chem. Eng. J. 2016, 285, 497-507. [CrossRef]

162. Luo, J.H.; Shen, P.; Yao, W.; Jiang, C.F.; Xu, J.G. Synthesis, characterization, and microwave absorption properties of reduced graphene oxide/strontium ferrite/polyaniline nanocomposites. Nanoscale Res. Lett. 2016, 11, 141. [CrossRef] [PubMed]

163. Yang, C.C.; Gung, Y.J.; Shih, C.C.; Hung, W.C.; Wu, K.H. Synthesis, infrared and microwave absorbing properties of (BaFe12O19+BaTiO3)/polyaniline composite. J. Magn. Magn. Mater. 2011, 323, 933-938. [CrossRef]

164. Chen, K.Y.; Xiang, C.; Li, L.C.; Qian, H.S.; Xiao, Q.S.; Xu, F. A novel ternary composite: Fabrication, performance and application of expanded graphite/polyaniline/ $\mathrm{CoFe}_{2} \mathrm{O}_{4}$ ferrite. J. Mater. Chem. 2012, 22, 6449-6455. [CrossRef]

165. Zhang, D.Q.; Cheng, J.Y.; Yang, X.Y.; Zhao, B.; Cao, M.S. Electromagnetic and microwave absorbing properties of magnetite nanoparticles decorated carbon nanotubes/polyaniline multiphase heterostructures. J. Mater. Sci. 2014, 49, 7221-7230. [CrossRef]

166. Liu, P.B.; Huang, Y.; Sun, X. Excellent electromagnetic absorption properties of poly(3,4-ethylenedioxythiophene)-reduced graphene oxide- $\mathrm{Co}_{3} \mathrm{O}_{4}$ composites prepared by a hydrothermal method. ACS Appl. Mater. Interfaces 2013, 5, 12355-12360. [CrossRef] [PubMed]

167. Liu, P.B.; Huang, Y.; Zhang, X. Superparamagnetic $\mathrm{NiFe}_{2} \mathrm{O}_{4}$ particles on poly(3,4-ethylenedioxythiophene)-graphene: Synthesis, characterization and their excellent microwave absorption properties. Compos. Sci. Technol. 2014, 95, 107-113. [CrossRef]

168. Liu, P.B.; Huang, Y.; Zhang, X. Cubic $\mathrm{NiFe}_{2} \mathrm{O}_{4}$ particles on graphene-polyaniline and their enhanced microwave absorption properties. Compos. Sci. Technol. 2015, 107, 54-60. [CrossRef]

169. Liu, P.B.; Huang, Y.; Zhang, X. Preparation and excellent microwave absorption properties of ferromagnetic graphene/poly(3,4-ethylenedioxythiophene)/ $\mathrm{CoFe}_{2} \mathrm{O}_{4}$ nanocomposites. Powder Technol. 2015, 276, 112-117. [CrossRef]

170. Liu, P.B.; Huang, Y.; Zhang, X. Synthesis and excellent microwave absorption properties of graphene/polypyrrole composites with $\mathrm{fe}_{3} \mathrm{O}_{4}$ particles prepared via a co-precipitation method. Mater. Lett. 2014, 129, 35-38. [CrossRef]

171. Liu, P.B.; Huang, Y.; Zhang, X. Synthesis, characterization and excellent electromagnetic wave absorption properties of graphene/poly(3,4-ethylenedioxythiophene) hybrid materials with $\mathrm{Fe}_{3} \mathrm{O}_{4}$ nanoparticles. J. Alloy Compd. 2014, 617, 511-517. [CrossRef] 
172. Ding, X.; Huang, Y.; Li, S.P.; Wang, J.G. Preparation and electromagnetic wave absorption properties of $\mathrm{FeNi}_{3}$ nanoalloys generated on graphene-polyaniline nanosheets. RSC Adv. 2016, 6, 31440-31447. [CrossRef]

173. Sambyal, P.; Singh, A.P.; Verma, M.; Farukh, M.; Singh, B.P.; Dhawan, S.K. Tailored polyaniline/barium strontium titanate/expanded graphite multiphase composite for efficient radar absorption. RSC Adv. 2014, 4, 12614-12624. [CrossRef]

174. Ni, Q.Q.; Zhu, Y.F.; Lu, L.J.; Fu, Y.Q. One-dimensional carbon nanotube@barium titanate@polyaniline multiheterostructures for microwave absorbing application. Nanoscale Res. Lett. 2015, 10, 174. [CrossRef] [PubMed]

175. Liu, C.Y.; Xu, Y.J.; Wu, L.N.; Jiang, Z.H.; Shen, B.Z.; Wang, Z.J. Fabrication of core-multishell MWCNT $/ \mathrm{Fe}_{3} \mathrm{O}_{4} / \mathrm{PANI} / \mathrm{Au}$ hybrid nanotubes with high-performance electromagnetic absorption. J. Mater. Chem. A 2015, 3, 10566-10572. [CrossRef]

176. Wang, L.; Zhu, J.F.; Yang, H.B.; Wang, F.; Qin, Y.; Zhao, T.; Zhang, P. Fabrication of hierarchical graphene@ $\mathrm{Fe}_{3} \mathrm{O}_{4} @ \mathrm{SiO}_{2} @$ polyaniline quaternary composite and its improved electrochemical performance. J. Alloy Compd. 2015, 634, 232-238. [CrossRef]

177. Ding, X.; Huang, Y.; Wang, J.G.; Wu, H.W.; Liu, P.B. Excellent electromagnetic wave absorption property of quaternary composites consisting of reduced graphene oxide, polyaniline and $\mathrm{FeNi}_{3} @ \mathrm{SiO}_{2}$ nanoparticles. Appl. Surf. Sci. 2015, 357, 908-914. [CrossRef]

178. Cui, S.M.; Weile, D.S.; Volakis, J.L. Novel planar electromagnetic absorber designs using genetic algorithms. IEEE Trans. Antenn. Propag. 2006, 54, 1811-1817. [CrossRef]

179. Cui, S.M.; Weile, D.S. Application of a parallel particle swarm optimization scheme to the design of electromagnetic absorbers. IEEE T. Antennas Propag. 2005, 53, 3616-3624. [CrossRef]

180. Gargama, H.; Chaturvedi, S.K.; Thakur, A.K. Design and optimization of multilayered electromagnetic shield using a real-coded genetic algorithm. Prog. Electromagn. Res. B 2012, 39, 241-266. [CrossRef]

181. Chen, M.X.; Zhu, Y.; Pan, Y.B.; Kou, H.M.; Xu, H.; Guo, J.K. Gradient multilayer structural design of $\mathrm{CNTs} / \mathrm{SiO}_{2}$ composites for improving microwave absorbing properties. Mater. Des. 2011, 32, 3013-3016. [CrossRef]

182. Melvin, G.J.H.; Ni, Q.Q.; Natsuki, T.; Wang, Z.P.; Morimoto, S.; Fujishige, M.; Takeuchi, K.; Hashimoto, Y.; Endo, M. Ag/CNT nanocomposites and their single- and double-layer electromagnetic wave absorption properties. Synth. Met. 2015, 209, 383-388. [CrossRef]

183. Micheli, D.; Pastore, R.; Gradoni, G.; Marchetti, M. Tunable nanostructured composite with built-in metallic wire-grid electrode. AIP Adv. 2013, 3, 112132. [CrossRef]

184. Micheli, D.; Apollo, A.; Pastore, R.; Marchetti, M. X-Band microwave characterization of carbon-based nanocomposite material, absorption capability comparison and RAS design simulation. Compos. Sci. Technol. 2010, 70, 400-409. [CrossRef]

185. Micheli, D.; Apollo, A.; Pastore, R.; Morles, R.B.; Laurenzi, S.; Marchetti, M. Nanostructured composite materials for electromagnetic interference shielding applications. Acta Astronaut. 2011, 69, 747-757. [CrossRef]

186. Xu, F.F.; Ma, L.; Huo, Q.S.; Gan, M.Y.; Tang, J.H. Microwave absorbing properties and structural design of microwave absorbers based on polyaniline and polyaniline/magnetite nanocomposite. J. Magn. Magn. Mater. 2015, 374, 311-316. [CrossRef]

187. Egami, Y.; Yamamoto, T.; Suzuki, K.; Yasuhara, T.; Higuchi, E.; Inoue, H. Stacked polypyrrole-coated non-woven fabric sheets for absorbing electromagnetic waves with extremely high frequencies. J. Mater. Sci. 2012, 47, 382-390. [CrossRef]

188. Micheli, D.; Vricella, A.; Pastore, R.; Marchetti, M. Synthesis and electromagnetic characterization of frequency selective radar absorbing materials using carbon nanopowders. Carbon 2014, 77, 756-774. [CrossRef]

(C) 2017 by the authors; licensee MDPI, Basel, Switzerland. This article is an open access article distributed under the terms and conditions of the Creative Commons Attribution (CC-BY) license (http://creativecommons.org/licenses/by/4.0/). 